Revista de Derecho

de la Pontificia Universidad Católica de Valparaíso

XXXV (Valparaíso, Chile, 2010, 2 Semestre)

[pp. 189 - 226]

\title{
LOS LÍMITES DE LA COSA JUZGADA EN El Derecho de la Unión Europea*
}

["The Limits of Res Judicata under European Union Law"]

\section{Carsten Kremer ${ }^{* *}$}

\section{RESUMEN}

El artículo intenta responder la pregunta de si existe o no y hasta qué punto una limitación a la cosa juzgada de sentencias nacionales de los Estados miembros de la Unión Europea; para lo cual se revisa ciertas sentencias importantes de los últimos años dictadas por el Tribunal de Justicia de la Unión Europea.

Palabras Clave: Precedente Cosa juzgada - Seguridad jurídica - Firmeza de una resolución administrativa - Responsabilidad del Estado - Recurso por incumplimiento.
Abstract

This article aims at answering the question whether there is, and if so, to what extent, a limitation to the res iudicata of the national decisions of the member States of the European Union. For this, certain important rulings, dating back to the past years, handed down by the Court of Justice of the European Union will be reviewed.

KEYwords: Precedent - Res iudicata - Legal certainty - Soundness of an administrative resolution - Responsibility of the State - Action for failure to fulfill an obligation.

*Traducción de Hannah Epple (ayudante de Derecho Procesal Penal Internacional y alumna de Derecho en la Universität Tübingen) y de Matías Aránguiz (ayudante de Derecho Procesal Civil y licenciado en Derecho en la Pontificia Universidad Católica de Chile) en colaboración con el autor Carsten Kremer. La traducción fue controlada y corregida por Álvaro Pérez Ragone (Pontificia Universidad Católica de Valparaíso) desde el original titulado "Gemeinschaftsrechtliche Grenzen der Rechtskraft".

** Licenciado en Ciencias Jurídicas (primer y segundo examen de Estado, München) y en Historia (Universität Freiburg), Magister Juris in European and Comparative Law (University of Oxford), Doctor en Derecho (Universität Frankfurt am Main). El autor es asistente científico en el Instituto de Derecho Público de la Universität Frankfurt am Main. Correo electrónico: c.kremer@jur.uni-frankfurt.de 


\section{INTRODUCCIÓN ${ }^{* * *}$}

Las decisiones judiciales que no pueden ser revisadas con un recurso legal, adquieren fuerza de cosa juzgada. Estas decisiones vinculan a las partes cuando finaliza el juicio ${ }^{1}$. La institución de la cosa juzgada es parte central de los ordenamientos jurídicos nacionales como del sistema del Derecho europeo, y el Tribunal de Justicia $(=\mathrm{TJ})^{2}$ recientemente reafirmó expresamente la "importancia" de la cosa juzgada ${ }^{3}$. Desde hace algún tiempo la jurisprudencia y la literatura se está encargando de responder hasta qué

*** El 1 de diciembre de 2009 entró en vigor el "Tratado de Lisboa”, que cambió el Tratado de la Unión Europea” (UE) y el Tratado de la Comunidad Europea” (CE). El Tratado de la Comunidad Europea se renombró como Tratado de Funcionamiento de la Unión Europea. Los tratados están disponibles en: http://eur-lex.europa.eu/es/ treaties/index.htm (15 de abril de 2010). El autor revisó el articulado para adaptarlo a las nuevas normas. Según el "Tratado de Lisboa", la Comunidad Europea ya no existe y es sustituida por la Unión Europea. A continuación, la expresión "Derecho comunitario" se utiliza solamente cuando se trata de la situación legal antigua antes de la entrada en vigor del "Tratado de Lisboa”. El nuevo término "Tribunal de Justicia de la Unión Europea” ahora incluye todos los tribunales de la Unión; véase el artículo 19 inciso $1^{\circ}$, párrafo primero, $1^{\text {a }}$ frase UE nueva versión: "El Tribunal de Justicia de la Unión Europea comprenderá el Tribunal de Justicia, el Tribunal General y los tribunales especializados". Las partes citadas de las sentencias del Tribunal de Justicia (TJ) se refieren a la versión oficial española de la respectiva sentencia. Se actualizó la citación de las sentencias y conclusiones de los abogados generales que hasta la publicación original en 2007 todavía no estaban en la "Recopilación de la Jurisprudencia" oficial. Los traductores agregaron una "Nota del Traductor" (N. d. T.) donde pareció importante.

${ }^{1}$ Con respecto al concepto de la cosa juzgada (formal y material) véase: RosenBerg, Leo - SCHwab, Karl Heinz - GotTwald, Peter, Zivilprozessrecht (16 a edición, München, Beck, 2004), pp. 1048 ss.; SCHEnke, Wolf-Rüdiger, Verwaltungsprozessrecht $\left(10^{a}\right.$ edición, Heidelberg, Müller, 2005), apartados 616 ss.; Kopp, Ferdinand - Schenke, Wolf-Rüdiger, Verwaltungsgerichtsordnung. Kommentar (14 edición, München, Beck, 2005), \$121 VwGO, apartado 2; DetTerbeck, Steffen, Streitgegenstand und Entscheidungswirkungen im Öffentlichen Recht (Tübingen, Mohr, 1995), p. 88.

${ }^{2}$ El Tribunal de Justicia es el órgano jurisdiccional central de la Unión Europea y constituye el Tribunal de Justicia de la Unión Europea junto con el Tribunal General y los tribunales especializados (véase, más arriba, la nota ${ }^{* * *}$ ).

${ }^{3} \mathrm{TJ}$, asunto C-234/04 ("Kapferer"), Rec. 2006, I-2585, apartado 20; véase ya asunto C-126/97 ("Eco Swiss"), Rec. 1999, I-3055, apartado 46; asunto C-224/01 (“Köbler”), Rec. 2003, I-10239, apartado 38. Sobre la cosa juzgada de decisiones del Tribunal de Justicia de Primera Instancia de la Unión Europea (TPI) véase por ejemplo TJ, asunto C-440/01 P(R) (“Artegodan GmbH”), Rec. 2002, I-1489, apartados 66, 70; asunto C-480/99 P (“South Wales Small Mines Association”), Rec. 2002, I-265, apartado 54; asuntos acumulados C-442/03 P y C-471/03 P ("P \& O European Ferries y Diputación Foral de Vizcaya/Comisión”), Rec. 2006, I-4845, apartados 40 ss. 
punto el Derecho de la Unión pone límites a la cosa juzgada de decisiones nacionales. La literatura ya constató que se "subvaloró masivamente" la cosa juzgada en la sentencia "Köbler" del Tribunal de Justicia ${ }^{4}$. Y en parte se interpreta la sentencia "Kühne \& Heitz" como un orden del Tribunal de "quebrantar la cosa juzgada"s. Este artículo quiere mostrar, cómo la última jurisprudencia del TJ está poniendo en duda progresivamente la cosa juzgada de sentencias nacionales y cómo puede reaccionar el ordenamiento jurídico frente a este desafío.

\section{LAS FUNCIONES DE LA COSA JUZGADA}

En primer lugar es necesario aclarar el sentido de la cosa juzgada para el Derecho nacional como para el Derecho de la Unión. Por un lado la institución de la cosa juzgada garantiza seguridad jurídica para los afectados de una decisión. Por otro lado se ve que es un componente importante para un ordenamiento jurídico que se define de manera decisiva por sentencias judiciales.

\section{Seguridad jurídica.}

La cosa juzgada es derivada, incluso por el $\mathrm{TJ}^{6}$, de la seguridad jurídica ${ }^{7}$, la cual es un principio fundamental del Derecho de la Unión según el mismo Tribunal ${ }^{8}$. La literatura del Derecho procesal alemán también describe este

${ }^{4}$ GUNDEL, Jörg, Gemeinschaftsrechtliche Haftungsvorgaben für judikatives Unrecht. Konsequenzen für die Rechtskraft und das deutsche "Richterprivileg" (5 839 Abs. 2 BGB, en Europäisches Wirtschafts- und Steuerrecht, 15 (2004) 1, p. 16 ("massiv unterbewertet").

${ }^{5}$ Kenntner, Markus, Ein Dreizack für die offene Flanke: Die neue EuGH-Rechtsprechung zur judikativen Gemeinschaftsrechtsverletzung, en Europäische Zeitschrift für Wirtschaftsrecht, 16 (2005) 8, pp. 237 s. ("Durchbruch der Rechtskraft").

${ }^{6}$ Véase TJ, asunto C-126/97 (“Eco Swiss”), Rec. 1999, I-3055, apartado 46: “[el principio] de seguridad jurídica y respeto de la cosa juzgada, que constituye su expresión"; véase: v. ARnAuld, Andreas, Rechtssicherheit (Tübingen, Mohr Siebeck, 2006), pp. 508 ss.

${ }^{7}$ Para más detalles, en general consúltese: v. Arnauld, cit. (n. 6), pp. 278 ss.

${ }^{8}$ Sobre la jurisprudencia antes de la entrada en vigor del "Tratado de Lisboa" (principios generales del Derecho comunitario), véase, por ejemplo: TJ, asunto 205-215/82 ("Deutsche Milchkontor"), Rec. 1983, 2633, apartado 30; asunto C-108/01 ("Consorzio del Prosciutto di Parma”), Rec. 2003, I-5121, apartados 89, 95; asunto C-459/02 (“Gerekens”), Rec. 2004, I-7315, apartados 22 ss.; asunto C-402/03 (“Skov”), Rec. 2006, I-199, apartado 51; en general sobre esto y con más citas v. ARNAULD, cit. (n. 6), pp. 497 ss.; Craig, Paul - De BúrCa, Gráinne, EU Law (3a edición, Oxford, Oxford University Press, 2003) pp. 380 ss. 
vínculo entre cosa juzgada y seguridad jurídica' ${ }^{9}$ Últimamente se demostró de nuevo que la seguridad jurídica no sólo es una "idea común europea" ("gemeineuropäische Idee"), sino también un principio constitucional del Grundgesetz ( $=\mathrm{GG}=$ Constitución alemana $)^{10}$. Por eso, es tarea principal de la función pública estatal garantizar la seguridad jurídica. A pesar de todo, la seguridad jurídica y con ella la cosa juzgada no sólo es un principio jurídico-objetivo. Sirve especialmente para proteger individuos cuyos derechos subjetivos fueron decididos por tribunales. Sentencias válidas aseguran posiciones de derechos que fueron cuestionados y producen fiabilidad para el individuo.

\section{Estabilización de normas jurídicas.}

Aparte de eso la cosa juzgada tiene otra función importante para el ámbito institucional de un ordenamiento jurídico moderno, el que no solamente puede ser constituido por la legislación o por codificaciones de leyes ${ }^{11}$. El Derecho tiene que ser reconocido o generado, aplicado o interpretado por tribunales en casos particulares. Por esto sirven las sentencias anteriormente falladas como base para diferenciar aún más los preceptos jurídicos. En el "Common Law" eso se realiza por el efecto del precedente ("precedent"), pero en los ordenamientos jurídicos nacionales continental-europeos existen efectos parecidos de sentencias judiciales ${ }^{12}$. Un ejemplo del Derecho público

${ }^{9}$ WÜRTEnBerger, Thomas, Verwaltungsprozessrecht (2a edición, München, Beck, 2006), apartado 242; DetTerbeCK, cit. (n. 1), pp. 89 s.

${ }^{10}$ Véase v. ARnAuld, cit. (n. 6), pp. 625 ss., pp. 664 ss.; sobre la cosa juzgada como "instituto del Derecho constitucional" ("Institut des Verfassungsrechts"), véase: DETTERBECK, cit. (n. 1), pp. 89 ss.

${ }^{11}$ Para más detalles sobre la crisis del principio de la codificación, véase: MEDER, Stephan, Die Krise des Nationalstaates und ihre Folgen für das Kodifikationsprinzip, en JuristenZeitung, 61 (2006) 10, pp. 477 ss.

${ }^{12}$ Zweigert, Konrad - KöTZ, Hein, Einführung in die Rechtsvergleichung (3a edición, Tübingen, Mohr, 1996) pp. 250 ss., sobre todo pp. 256 s., sobre la "realidad del Derecho" ("Rechtswirklichkeit") en el continente: "Apenas es una exageración decir que la doctrinca stare decisis del Common Law y la práctica respectiva de los tribunales continentales llevan a los mismos resultados en gran parte." ("Es ist daher wohl kaum eine Übertreibung, wenn man sagt, daß die stare-decisis-Doktrin des Common Law und die entsprechende Praxis der kontinentalen Gerichte weithin zu gleichen Ergebnissen führen."). Para más detalles sobre la significancia de casos prejudiciales para el Derecho alemán, sobre la pregunta si decisiones judiciales son parte de las fuentes del Derecho y acerca de si existe un "Derecho de jueces" ("Richterrecht"), consúltese, por ejemplo, aunque con acentuación distintas: LAREnz, Karl, Methodenlehre der Rechtswissenschaft ( $6^{a}$ edición, Berlin y otras, Springer, 1991), pp. 429 ss.; LAMEs, Peter, Rechtsfortbildung als Prozeßzweck. Zur Dogmatik des Zivilverfahrensrechts (Tübingen, Mohr, 1993), pp. 19 ss.; BREHM, Wolfgang, Rechtsfortbildungszweck des Zivilprozesses, 
alemán es el Derecho de la responsabilidad del Estado. Aquí, los tribunales afirman, seguros en sí mismos, la existencia de un "Derecho judicial" ("Richterrecht") ${ }^{13}$. El jurista Ossenbühl afirmó con razón, que el Derecho de la responsabilidad del Estado era "case law en las partes esenciales"14.

El TJ técnicamente no está obligado a fallar respecto del precedente. Sin embargo, en la práctica sí sigue sus sentencias anteriores ${ }^{15}$. Aparte de esto el TJ exige de los tribunales nacionales que sigan sus sentencias, aunque no estén incluidos en el caso que dio origen a la sentencia (por ejemplo por una petición de cuestión prejudicial). En este sentido, en la literatura se habla de un efecto vinculante de las sentencias que resultaron del procedimiento de cuestiones prejudiciales según artículo 267 del Tratado de Funcionamiento de la Unión Europea, en adelante TFUE ${ }^{16}$ (antiguo artículo 234 del Tra-

en: Festschrift für Ekkehard Schumann zum 70. Geburtstag (Tübingen, Mohr Siebeck, 2001), pp. 57 ss.; OssenbüHL, Fritz, Arten der Rechtsquellen, en Erichsen, HansUwe - Ehlers, Dirk (editores), Allgemeines Verwaltungsrecht (12 ${ }^{\mathrm{a}}$ edición, Berlin, De Gruyter, 2002), \$6, apartados 74 ss.; BADURA, Peter, Die Bedeutung von Präjudizien im öffentlichen Recht, en Blaurock, Uwe (editor), Die Bedeutung von Präjudizien im deutschen und französischen Recht (Frankfurt am Main, Metzner, 1985), pp. 49 ss.

${ }^{13}$ Véase: Bundesgerichtshof (BGH = Tribunal Federal Supremo Alemán), Neue Juristische Wochenschrift (2005), pp. 1363 s.: "base del instituto de responsabilidad de la intervención enajenable caracterizado y ampliado judicialmente" "Grundlage des richterrechtlich geprägten und ausgestalteten Haftungsinstituts des enteignenden Eingriffs"); BGHZ [N. d. T.: Recopilación oficial de sentencias del Derecho civil del BGH) 136, 182 (186]: el "instituto de responsabilidad de la intervención igual a enajenación" ("richterrechtliche Haftungsinstitut des enteignungsgleichen Eingriffs").

${ }^{14}$ OssenbüHL, Fritz, Staatshaftungsrecht ( $5^{\text {a }}$ edición, München, Beck, 1998), p. 3 ("in wesentlichen Partien case law").

${ }^{15}$ Más detalles en: Arnull, Anthony, Interpretation and Precedent in European Community Law, en Andenas, Mads - Jacobs, Francis (editores), European Community Law in the English Courts (Oxford, Oxford University Press, 1998), pp. 125 ss. con más citas; Weatherill, Stephen - Beaumont, Paul, EU Law (3 $3^{\mathrm{a}}$ edición, London, Penguin Books, 1999) pp. 201 ss. Para más detalles sobre el "efecto de precedente” ausente de sentencias de los tribunales de la Unión Europea, véanse también las conclusiones del abogado general Trstenjak en el asunto C-331/05 P ("Internationaler Hilfsfonds e.V./Comisión"), Rec. 2007, I-5475, apartado 85.

${ }^{16}$ [N. d. T.: El procedimiento del artículo 267 TFUE (antiguo artículo 234 CE) obliga a tribunales nacionales plantear ciertas cuestiones sobre el Tratado de la Unión Europea o el Tratado de Funcionamiento de la Unión Europea y su aplicación ante el TJ. La función de la norma es garantizar la uniformidad del Derecho europeo en toda la Unión y evitar que surjan por los tribunales interpretaciones nacionales distintas entre país y país de las normas europeas. Texto del artículo 267 TFUE: "El Tribunal de Justicia de la Unión Europea será competente para pronunciarse, con carácter prejudicial:/ a) sobre la interpretación de los Tratados; / b) sobre la validez e interpretación de los actos adoptados por las instituciones, órganos u organismos de la Unión./ Cuando se plantee una cuestión de esta naturaleza ante un órgano jurisdiccional de uno de los Estados 
tado de la Comunidad Europea, en adelante CE), sin embargo, ese efecto vinculante se reduce sobre todo con respecto a sentencias interpretativas (al contrario de sentencias que constan la invalidez de un acto o una medida) con palabras como "verdadero" ("tatsächlich") ${ }^{17}$. Además, divergiendo de la letra del artículo 267 inciso $3^{\circ}$ TFUE (antiguo artículo 234 inciso $3^{\circ} \mathrm{CE}$ ), el $\mathrm{TJ}$ permite no plantear en juicio discusiones ya resueltas y con jurisdicción asegurada del mismo Tribunal ${ }^{18}$. Este punto de vista solamente puede ser sensato si en principio existe una obligación para los tribunales nacionales de seguir las sentencias del TJ.

El presupuesto esencial para estas conclusiones e interpretaciones de la jurisprudencia, es que una sentencia fallada tiene existencia en el futuro y presunción de veracidad. Elementos los cuales se pueden esperar más aun en las sentencias dictadas por instancias superiores que adquirieron fuerza de cosa juzgada, es decir, que no pueden volver a ser revisadas. Bien es verdad que existe una diferencia fundamental entre cosa juzgada y precedente ("Präjudizwirkung") ${ }^{19}$. Según lo anterior, de acuerdo al $\$ 121 \mathrm{~N}^{\circ} 1$ Verwaltungsgerichtsordnung ( $\mathrm{VwGO}=$ Código Procesal Administrativo) las sentencias válidas, en principio, sólo obligan a las partes de un juicio y sus sucesores jurídicos cuando fue fallado sobre el objeto del juicio. Sin embargo, la literatura indica que exactamente la "fuerza vinculante especial" ("besondere Geltungskraft”) de las sentencias o, que se manifiesta en su cosa juzgada, ejecutoriedad y su efecto constitutivo, es la que pone mayor peso a la exigencia

miembros, dicho órgano podrá pedir al Tribunal que se pronuncie sobre la misma, si estima necesaria una decisión al respecto para poder emitir su fallo./ Cuando se plantee una cuestión de este tipo en un asunto pendiente ante un órgano jurisdiccional nacional, cuyas decisiones no sean susceptibles de ulterior recurso judicial de Derecho interno, dicho órgano estará obligado a someter la cuestión al Tribunal./ Cuando se plantee una cuestión de este tipo en un asunto pendiente ante un órgano jurisdiccional nacional en relación con una persona privada de libertad, el Tribunal de Justicia de la Unión Europea se pronunciará con la mayor brevedad"].

${ }^{17}$ Bieber, Roland, Epiney, Astrid - HaAg, Marcel, Die Europäische Union (7 $7^{\mathrm{a}}$ edición, Baden-Baden, Nomos, 2006), $\$ 9$, apartados 107 ss.; véase también KADELBACH, Stefan, Die Wirkung von im Vorabentscheidungsverfahren ergangenen Urteilen, en HoLoubek, Michael - Lang, Michael (editores), Das EuGH-Verfahren in Steuersachen (Wien, Linde, 2000), pp. 119 ss.; además ArNull, cit. (n. 15), pp. 134 ss.

${ }^{18}$ TJ, asunto 283/81 (“CILFIT”), Rec. 1982, 3415, apartado 14.

${ }^{19}$ Véase por ejemplo LARENZ, cit. (n. 12), p. 429; BADURA, cit. (n. 12), pp. 51 ss.; Clausing, Berthold, Kommentierung von $\$ 121 \mathrm{VwGO}$ [actualizado Febrero de 1996], en Sсносн, Friedrich - Schmidt-Assmann, Eberhard - Pietzner, Rainer (editores), Verwaltungsgerichtsordnung. Kommentar (München, Beck, 1996), \$121 VwGO, apartado 42; Hergenröder, Curt Wolfgang, Zivilprozessuale Grundlagen richterlicher Rechtsfortbildung (Tübingen, Mohr, 1995), pp. 227 ss., 231. 
de considerar las sentencias en juicios futuros ${ }^{20}$. Con respecto a eso, la cosa juzgada tiene una función importante para el desarrollo del derecho ${ }^{21}$. Para el Derecho de la Unión Europea la institución de la cosa juzgada tiene aún más importancia, porque la interpretación y formación del Derecho de la Unión se realiza a través del TJ, el cual necesita de los tribunales nacionales para implementar y aplicar su jurisdicción de una manera descentralizada. Eso explica muy bien por qué el TJ realza la importancia de la cosa juzgada, aunque últimamente su jurisdicción la cuestionó implícitamente con respecto a los tribunales de los Estados miembros. Esto se ve especialmente en el caso "Köbler"”2.

\section{LÍMITES A LA COSA JUZGADA DE SENTENCIAS JUDICIALES nacionales en el Derecho de la Unión Europea}

\section{Conflicto de principios.}

Desde una perspectiva del Derecho de la Unión, el principio de la seguridad jurídica está en conflicto con el objetivo de asegurar la efectividad del Derecho de la Unión, el que reclama primacía sobre los Derechos nacionales ${ }^{23}$. Si se mirara solamente el principio de efectividad del Derecho europeo ${ }^{24}$, se tendría que exigir que todas las sentencias de los tribunales nacionales que no estén de acuerdo con el Derecho de la Unión fueran corregidas, aunque estas ya estuvieran firmes. Además, el amparo eficaz de los derechos individuales que garantiza el Derecho de la Unión puede oponerse al principio de la seguridad jurídica, por ejemplo si una sentencia firme pero ilegítima priva a un individuo de su derecho reconocido por el Derecho de la Unión.

Una restricción de la cosa juzgada de sentencias nacionales por el Derecho de la Unión afectaría la autonomía de los Estados miembros. Sería

${ }^{20}$ LAMES, cit. (n. 12), pp. 31 ss. (también sobre las paralelas entre el efecto de cosa juzgada material y el efecto del desarrollo del Derecho de la sentencia).

${ }^{21}$ Sobre eso también LAMES, cit. (n. 12), p. 32.

${ }^{22}$ Sobre eso véase abajo III 2 y 6.

${ }^{23}$ Para más detalles sobre la primacía del Derecho de la Unión, respectivamente la primacía del Derecho comunitario, consúltese: Kadelbach, Stefan, Allgemeines Verwaltungsrecht unter europäischem Einfluß (Tübingen, Mohr Siebeck, 1999), pp. 54 ss.; Wegener, Bernhard W., Kommentierung von Art. 220 EG, en Calliess, Christian - Ruffert, Matthias (editores), EUV/EGV. Das Verfassungsrecht der Europäischen Union mit Europäischer Grundrechtecharta. Kommentar ( $3^{a}$ edición, München, Beck, 2007), Art. 220 CE, apartados 27 ss.; BieBer, EpINey - HaAG, cit. (n. 17), §3, apartados 31 ss.; STREInZ, Rudolf, Europarecht ( $7^{a}$ edición, Heidelberg, C.F. Müller, 2005) apartados 190 ss.

${ }^{24}$ Para más detalles sobre este principio, consúltese: KADELBACH, cit. (n. 23), pp. 115 ss.; BIEBER, EPINEy - HAAG, cit. (n. 17), §8, apartado 16. 
una "afectación" porque el Derecho de la Unión depende mucho de su ejecución indirecta por las autoridades y tribunales nacionales de acuerdo con los respectivos ordenamientos jurídicos nacionales. Por eso se habla del principio de la autonomía institucional y procesal de los Estados miembros. El TJ reconoció este principio tempranamente y lo restringió sobre todo a través del principio de la prohibición de discriminación y el principio de la efectividad ${ }^{25}$.

Muchas veces el Tribunal de Justicia utiliza redacciones las cuales unen principios diferentes o incluso contradictorios y que permiten una ponderación distinta dependiente de los antecedentes del caso. Lo mismo ocurrió con la cosa juzgada, lo cual es aclarado especialmente en las decisiones "Köbler y Traghetti”.

\section{Responsabilidad del Estado.}

La ampliación de la jurisprudencia Francovich al Poder Judicial por decisión del TJ en el caso "Köbler" causó un debilitamiento considerable para la cosa juzgada. Ahora el Estado puede ser responsable en caso de violación del Derecho de la Unión por tribunales nacionales de última instancia, cuando se cumplen ciertos requisitos ${ }^{26}$. Esta sentencia era el último componente para un sistema de responsabilidad coherente en caso de violación del Derecho de la Unión por los Estados miembros ${ }^{27}$. El caso “Traghetti” afirmó y mantuvo el razonamiento de la decisión "Köbler". En el juicio desarrollado en el Estado miembro que dio pie a la intervención del TJ la parte actora demandó a Italia una indemnización porque la Corte Suprema di Cassazione (Italia) había infringido el Derecho comunitario europeo ${ }^{28}$ y no había planteado

${ }^{25}$ Bieber, EPINey - HaAG, cit. (n. 17), $\$ 8$, apartados 11, 16 ss.; KAdelbach, cit. (n. 23), pp. 110 ss. (autonomía de la ejecución), pp. 115 ss. (principios limitativos de la autonomía); Craig - De BúrCa, cit. (n. 8), pp. 230 ss.; Potacs, Michael, Bestandskraft staatlicher Verwaltungsakte oder Effektivität des Gemeinschaftsrechts?, en Europarecht, 39 (2004) 4, pp. 596 ss.

${ }^{26}$ TJ, asunto C-224/01 (“Köbler”), Rec. 2003, I-10239, apartados 30 ss., 51 ss.

${ }^{27}$ Véase: KLuth, Winfried, Die Haftung der Mitgliedstaaten für gemeinschaftsrechtswidrige höchstrichterliche Entscheidungen. Schlussstein im System der gemeinschaftsrechtlichen Staatshaftung, en Deutsches Verwaltungsblatt, 119 (2004) 7, sobre todo p. 399: "perfección sistemática" ("systematische Vollendung"). Para más detalles sobre los casos de responsabilidad, consúltese: KREMER, Carsten, Liability for Breach of European Community Law: An Analysis of the New Remedy in the Light of English and German Law, en Yearbook of European Law, 22 (2003), pp. 204 s.

${ }^{28}$ Hoy en día, después de la entrada en vigor del "Tratado de Lisboa”, no se preguntaría si había una infracción del Derecho comunitario, mas si la Corte Suprema di Cassazione infringió el Derecho de la Unión (sobre el término "Derecho comunitario" véase, más arriba, la nota ${ }^{* * *}$ ). 
una cuestión prejudicial lo cual iba en contra del artículo 234 inciso $3^{\circ} \mathrm{CE}$ (actualmente artículo 267 inciso $3^{\circ}$ TFUE). Sin embargo, según el Derecho italiano la responsabilidad por error judicial existe sólo de manera limitada. La norma que excluyó la responsabilidad por la interpretación de leyes y por la estimación incorrecta de hechos y pruebas no perduró ante el TJ, puesto que este la derogó. Además, el TJ decidió con respecto al ordenamiento jurídico italiano que el Derecho comunitario se opone a normas que limiten la responsabilidad del Estado a casos de actuación dolosas o que sean realizadas con culpa grave, si esto excluye la responsabilidad de casos que cumplen con los requisitos de la decisión "Köbler" ${ }^{29}$. Con esto se le dice indirectamente por el TJ a los tribunales nacionales de máxima instancia que para evitar responsabilidad deberán plantearle, en caso de dudas, las preguntas sobre la interpretación del Derecho de la Unión, según el artículo 267 inciso $3^{\circ}$ TFUE (antiguo artículo 234 inciso $3^{\circ} \mathrm{CE}$ ).

La responsabilidad del Estado afecta solamente sentencias que producen efecto de cosa juzgada. Eso se deriva del hecho de que el Estado solo es responsable en el caso de sentencias de última instancia, o sea, las que no pueden ser revisadas con recurso alguno y por tanto producen efecto pleno de cosa juzgada ${ }^{30}$. Durante el procedimiento del caso "Köbler" varios gobiernos nacionales presentaron argumentos contra la responsabilidad del Poder Judicial ante el TJ. Precisamente el significado de la cosa juzgada para el TJ no era un argumento para excluir de principio una responsabilidad por decisiones judiciales, como lo alegaron algunos gobiernos ${ }^{31}$. El TJ mismo se refirió al problema y reafirmó la importancia del principio de la cosa juzgada. Sin embargo, según el TJ el reconocimiento del principio de la responsabilidad del Estado no cuestiona la cosa juzgada de las decisiones judiciales, porque

${ }^{29} \mathrm{TJ}$, asunto C-173/03 (“Traghetti”), Rec. 2006, I-5177, apartados 30 ss., 33 ss., 42 ss. Sin embargo, sería exagerado interpretar la sentencia "Traghetti" como un endurecimiento, comparado con la jurisprudencia "Köbler" (lo cual, empero, sostiene LiNDNER, Josef Franz, "Anmerkung", en Bayerische Verwaltungsblätter, 137 (2006) 22, p. 697). Para más detalles sobre esta sentencia, consúltese también: SEEgERs, Martin, "Anmerkung”, en Europäische Zeitschrift für Wirtschaftsrecht, 17 (2006) 18, pp. 564 ss.; HaratsCh, Andreas, "Anmerkung zum Urteil des EuGH v. 13.6.2006, Rs. C-173/03 (“TDM/Italien”)", en JuristenZeitung, 61 (2006) 23, pp. 1.176 ss.; Tietjen, Daniel, Die Bedeutung der deutschen Richterprivilegien im System des gemeinschaftsrechtlichen Staatshaftungsrechts. Das EuGH-Urteil "Traghetti del Mediterraneo", en Europäisches Wirtschafts- und Steuerrecht, 18 (2007) 1, pp. 15 ss.; RufferT, Matthias, Annotation: Case C-173/03: "Traghetti del Mediterraneo SpA in Liquidation v. Italian Republic", en Common Market Law Review, 44 (2007) 2, pp. 479 ss.

${ }^{30}$ Véase: TJ, asunto C-224/01 (“Köbler"), Rec. 2003, I-10239, apartados 33 ss.

${ }^{31}$ Véase TJ, asunto C-224/01 (“Köbler”), Rec. 2003, I-10239, apartados 16 ss., 18, $20,23,25$. 
un procedimiento que genere responsabilidad del Estado no tiene el mismo objeto ni es necesario que tenga las mismas partes del juicio sino solo que se refiera a la obligación de hacer el procedimiento de consulta, y que en el caso anterior no se haya dado. Además el TJ agregó que el "principio de la responsabilidad del Estado inherente al ordenamiento jurídico comunitario" sólo exige una indemnización, pero no la modificación de la decisión judicial que causó el daño ${ }^{32}$.

Mientras tanto, esta argumentación del TJ convence solo a primera vista, ya que está basada en meras categorías formales como el objeto del proceso de un juicio. Aunque el juicio sobre la responsabilidad del Estado trate otro objeto del proceso, de alguna manera indirecta sí cuestiona el resultado de la sentencia firme anterior y la corrige a través de la indemnización de perjuicios. Entonces, este juicio no cuestiona la existencia de la resolución, pero sí hace un reproche a su contenido por medio de la indemnización ${ }^{33}$. En otras palabras: El "efecto de satisfacción" ("Befriedungswirkung") que debería tener tal decisión firme, sería "revocado" (“aufgehoben”) ${ }^{34}$. Por ende, en la literatura se habla con razón de una "relativización grave de la cosa juzgada" ("starke Relativierung der Rechtskraft") por la sentencia "Köbler"35.

No obstante, el TJ toma en consideración la "especificidad de la función

${ }^{32}$ TJ, asunto C-224/01 ("Köbler"), Rec. 2003, I-10239, apartados 37 ss.; véanse también las conclusiones del abogado general Léger en el asunto C-224/01 (“Köbler”), Rec. 2003, I-10239, apartados 101 ss.

${ }^{33}$ Así la diferenciación en Wegener, Bernhard W., Staatshaftung für die Verletzung von Gemeinschaftsrecht durch nationale Gerichte?, en Europarecht, 37 (2002) 6, p. 794, nota 49; RADERMACHER, Ludger, Gemeinschaftsrechtliche Staatshaftung für höchstrichterliche Entscheidungen, en Neue Zeitschrift für Verwaltungsrecht, 23 (2004) 12, p. 1.418.

${ }^{34}$ GRUne, Jeanette, Staatshaftung bei Verstößen nationaler Gerichte gegen Europäisches Gemeinschaftsrecht, en Bayerische Verwaltungsblätter, 135 (2004) 22, p. 676; véase también RADERMACHER, cit. (n. 33), p. 1.418.

${ }^{35}$ Schöndorf-Haubold, Bettina, Die Haftung der Mitgliedstaaten für die Verletzung von EG-Recht durch nationale Gerichte, en Juristische Schulung, 46 (2006) 2, p. 115; además véase GuNDEL, cit. (n. 4), p. 16 (véase, más arriba, I); KREMER, Carsten, Staatshaftung für Verstöße gegen Gemeinschaftsrecht durch letztinstanzliche Gerichte, en Neue Juristische Wochenschrift, 57 (2004) 8, p. 481, quien cuestiona indirectamente el contenido de una decisión que produjo efecto de cosa juzgada; STORR, Stefan, Abschied vom Spruchrichterprivileg?, en Die Öffentliche Verwaltung, 57 (2004) 13, p. 553: "a cuenta de la seguridad jurídica se debilita la función de la cosa juzgada"; WATTEL, Peter J., "Köbler, CILFIT and Welthgrove": We Can't Go on Meeting Like This, en Common Market Law Review, 41 (2004) 1, p. 177: the ECJ "essentially ignores that principle" of res judicata; véase también: KOMÁreK, Jan, Federal Elements in the Community Judicial System: Building Coherence in the Community Legal Order, en Common Market Law Review, 42 (2005) 1, p. 27; Ruffert, cit. (n. 29), pp. 480, 484 s. 
jurisdiccional y las exigencias legítimas de seguridad jurídica" cuando formula los requisitos de la responsabilidad. Refiriéndose al requisito de una violación suficientemente caracterizada del Derecho comunitario respectivamente del Derecho de la Unión declara el Tribunal -distinto a otros casos de responsabilidad- que sólo infracciones manifiestas por el Poder Judicial resultan en una responsabilidad ${ }^{36}$. Aquí hace sentido compararlo con la situación legal alemana, donde se protege aún más la seguridad jurídica. En del Derecho de la responsabilidad administrativa ("Amtshaftungsrecht") alemana, según $\$ 839$ inciso $2^{\circ}$ Bürgerliches Gesetzbuch ( $\mathrm{BGB}=$ Código Civil alemán) ${ }^{37}$ tampoco se excluye una responsabilidad por incumplimiento de deber del juez, pero la existencia de una responsabilidad en el párrafo antes referido, exige que se haya cometido prevaricación al mismo tiempo. Este requisito especial persigue sobre todo el aseguramiento de la cosa juzgada de sentencias judiciales ${ }^{38}$. Sin embargo, esto es una restricción importante del ámbito de aplicación de la responsabilidad del Estado por decisiones judiciales, en todo es más fácil que se alcancen los requisitos en el Derecho europeo que en el Derecho alemán. Una infracción manifiesta en el Derecho de la Unión no tiene que tener el nivel de un delito penal (por ejemplo una prevaricación intencional). En el caso "Köbler", el Gobierno alemán había intentado sin éxito establecer el sentido y alcance del $\$ 839$ inciso $2^{\circ} \mathrm{BGB}$ a nivel del Derecho europeo ${ }^{39}$. Por ende, ahora o no se puede aplicar la norma alemana en casos con relación al Derecho de la Unión ${ }^{40}$ o se tiene que interpretar la norma conforme al Derecho de la Unión, así que no se requiere de un cumplimiento de un tipo penal, sino sólo una violación suficientemente caracterizada ${ }^{41}$.

Finalmente se puede constatar, que el TJ en la decisión "Köbler" se esforzó en encontrar un compromiso entre los principios contradictorios de la efec-

${ }^{36} \mathrm{TJ}$, asunto C-224/01 (“Köbler”), Rec. 2003, I-10239, Rn. 53.

${ }^{37}$ [N. d. T.: $\$ 839$ inciso 2 BGB dice: "Si un funcionario infringe su deber profesional al dictar sentencia en un pleito, no es responsable de ningún daño que aparezca por esto, a menos que la infracción del deber esté castigado con una pena pública a imponer por vía judicial penal. Esta disposición no se aplica a la infracción del deber consistente en la negativa o la demora en el ejercicio de la función"].

${ }^{38}$ OssenbüHL, cit. (n. 14), pp. 101 s.; WINDThORSt, Kay, Begrenzung der Amtshaftung, en: Detterbeck, Steffen - Windthorst, Kay - Sproll, Hans-Dieter, Staatshaftungsrecht (München, Beck, 2000), \$10, apartado 38 y s.; STORR, cit. (n. 35), pp. 545 s.; sostiene otra opinion: Wolf, Christian, Die (un-) dramatischen Auswirkungen der Köbler-Entscheidung des EuGH auf das gemeinschaftsrechtliche Staatshaftungsrecht und das deutsche Revisionsrecht, en Wertpapier-Mitteilungen, 59 (2005) 29, p. 1.347.

${ }^{39}$ KREMER, cit. (n. 35), p. 482.

${ }^{40}$ Gundel, cit. (n. 4), p. 16; Schöndorf-Haubold, cit. (n. 35), p. 114; TietJEN, cit. (n. 29), p. 18.

${ }^{41}$ KLUTH, cit. (n. 27), p. 402. 
tividad del Derecho de la Unión y el amparo de los derechos del individuo y por otro lado de la seguridad jurídica. Si bien se afirmó la existencia de una responsabilidad, al mismo tiempo se establecieron requisitos estrictos para la responsabilidad, cuyo cumplimiento debería ser una excepción.

\section{Recurso por incumplimiento.}

Otra situación que permite, en principio, la revisión de una sentencia firme es el recurso por incumplimiento ${ }^{42}$ según artículos 258 y ss. TFUE (antiguos artículos 226 y ss. CE). Sobre todo el artículo 258 TFUE $^{43}$ (antiguo artículo $226 \mathrm{CE}$ ) tiene relevancia, según el cual la Comisión Europea (en adelante "la Comisión") puede recurrir al TJ si un Estado miembro incumplió una de las obligaciones que le incumben en virtud del Tratado de la Unión Europea o del Tratado de Funcionamiento de la Unión Europea. El TFUE no excluye que las decisiones judiciales nacionales puedan violar en nombre del Estado a los mismos Tratados y en la literatura se reconoce que éstas pueden ser objeto de un recurso por incumplimiento ${ }^{44}$, de lo cual ya ha habido casos. Antes de ver un caso de violación de contrato ante el TJ, la Comisión pide formalmente o informalmente al Estado miembro, opinar respecto al asunto ${ }^{45}$, luego de lo cual es posible, que el Estado miembro y la Comisión concluyen el asunto de común acuerdo o que la Comisión efectúe o no medidas contra el Estado miembro e interponga una demanda ${ }^{46}$. De esta manera la Comisión ya ha realizado vario conflictos por incumplimiento que trataron sobre sentencias judiciales nacionales en contra del Derecho comunitario $^{47}$, los cuales nunca han llegado a juicio con la sentencia misma

${ }^{42}$ [N. de T.: "Incumplimiento" se refiere al incumplimiento de las disposiciones del Tratado de Funcionamiento de la Unión Europea por un Estado miembro, es decir, un incumplimiento del Derecho de la Unión Europea].

${ }^{43}$ [N. d. T.: Artículo 258 TFUE (antiguo artículo 226 CE): "Si la Comisión estimare que un Estado miembro ha incumplido una de las obligaciones que le incumben en virtud de los Tratados, emitirá un dictamen motivado al respecto, después de haber ofrecido a dicho Estado la posibilidad de presentar sus observaciones./ Si el Estado de que se trate no se atuviere a este dictamen en el plazo determinado por la Comisión, ésta podrá recurrir al Tribunal de Justicia de la Unión Europea"].

${ }^{44}$ Cremer, Wolfram, Kommentierung von Art. 226 EG, en: Calliess, Christian - Ruffert, Matthias (editores), EUV/EGV. Das Verfassungsrecht der Europäischen Union mit Europäischer Grundrechtecharta. Kommentar ( $3^{\mathrm{a}}$ edición, München, Beck, 2007), Art. 226 CE, apartado 28; Weatherill - BeAumont, cit. (n. 15), p. 225; además, véase: CRAIG - DE BúRCA, cit. (n. 8), p. 424.

${ }^{45}$ Para más detalles sobre las actuaciones preliminares informales y formales, consúltese: Cremer, cit. (n. 44), Art. 226 CE, apartados 1, 5 ss.

${ }^{46}$ Véase: CREMER, cit. (n. 44), Art. 226 CE, apartados 40 ss., allá también tratando los problemas por separados y opiniones divergentes.

${ }^{47}$ Véase sobre esto los ejemplos (distintos) de: HaLtern, Ulrich, Verschiebungen 
como objeto del procedimiento. La razón para esta reserva ha sido el respeto por la independencia judicial ${ }^{48}$. No obstante sí ha habido casos en los que la Comisión adoptó medidas contra la actuación administrativa previa o posterior a la decisión judicial ${ }^{49}$.

Poco tiempo después de la decisión "Köbler" el TJ vio un caso donde trató una violación de contrato por tribunales italianos ("Comisión/Italia"). Italia aprobó una ley que contuvo normas sobre la ejecución de obligaciones de Derecho comunitario. Entre otras, había una norma sobre el reembolso de impuestos de una ley que iban contra el Derecho comunitario. Mirando solamente la norma se podría pensar que era compatible con el Derecho comunitario, pero en la práctica se habían formado un tratamiento administrativo y una jurisprudencia que según la opinión de la Comisión estaban en contra del Derecho comunitario, entre estas especialmente la jurisprudencia de la Corte Suprema di Cassazione (Italia). En vista de esto, el abogado general Geelhoed se ocupó mucho del tema de incumplimiento por jurisprudencia nacional ${ }^{50}$, para él, el problema tenía una relación estrecha con la responsabilidad del Estado por el Poder Judicial y se refirió a las conclusiones de abogado general Léger en el caso "Köbler". El abogado general Geelhoed argumentó que el Estado miembro es una unidad con respecto al cumplimiento de obligaciones del contrato y por ende la jurisprudencia nacional podía ser causa para iniciar un recurso de incumplimiento ${ }^{51}$. El TJ mismo,

im europäischen Rechtsschutzsystem, en Verwaltungsarchiv, 96 (2005) 3, pp. 328 s., nota 58; MEIER, Gert, Zur Einwirkung des Gemeinschaftsrechts auf nationales Verfahrensrecht im Falle höchstrichterlicher Vertragsverletzungen, en Europäische Zeitschrift für Wirtschaftsrecht, 2 (1991) 1, p. 11; BREUER, Marten, Urteile mitgliedstaatlicher Gerichte als möglicher Gegenstand eines Vertragsverletzungsverfahrens gem. Art. 226 EG?, en Europäische Zeitschrift für Wirtschaftsrecht, 15 (2004) 7, p. 200; WEATHERILL BEAUMONT, cit. (n. 15), p. 225; además SACK, Jörn, Verstoßverfahren und höchstrichterliche Vertragsverletzungen - eine Klarstellung, en Europäische Zeitschrift für Wirtschaftsrecht, 2 (1991) 8, p. 247.

${ }^{48}$ Véase: Weatherill - Beaumont, cit. (n. 15), p. 225, los cuales citan un informe de la Comisión; además SACK, cit. (n. 47), p. 247; BreUER, cit. (n. 47), p. 200. Véanse también las conclusiones del abogado general Tizzano, en el asunto C-99/00 (“Lyckeskog”), Rec. 2002, I-4839, apartado 65: La Comisión consideraba "acertadamente" que en cuanto a infracciones contra la obligación de plantear cuestiones prejudiciales el recurso por incumplimiento previsto en el artículo $226 \mathrm{CE}$ (actualmente artículo 258 TFUE) "no puede prácticamente utilizarse y ni siquiera es oportuno".

${ }^{49}$ Véase SACK, cit. (n. 47), p. 247.

${ }^{50}$ Véanse las conclusiones del abogado general Warner, en el asunto 30/77 (“Bouchereau”), Rec. 1977, 1999, pp. 2015 ss., p. 2020, según el cual un incumplimiento solamente era posible si un tribunal nacional no consideraba el Derecho comunitario intencionalmente.

${ }^{51}$ Conclusiones del abogado general Geelhoed, en el asunto C-129/00 (“Comi- 
en cambio, evitó tomar una postura tan clara, se remitió a una decisión del año 1970 y constató que en principio se puede declarar un incumplimiento independiente del órgano estatal que causó el incumplimiento, "incluso cuando se trata de una institución constitucionalmente independiente" 52 . Sin embargo parece ser claro que se pueden revisar decisiones judiciales con respecto al Derecho de la Unión por medio del procedimiento según artículo 258 TFUE (antiguo artículo $226 \mathrm{CE}$ ). Desde el punto de vista nacional eso no es nada nuevo, pues las decisiones judiciales alemanas son objeto de procedimientos ante el Tribunal Europeo de Derechos Humanos. Si los tribunales alemanes infraccionan el "Convenio Europeo para la Protección de los Derechos Humanos y de las Libertades Fundamentales” (CEDH), el Tribunal Europeo de Derechos Humanos constata este incumplimiento ${ }^{53}$.

No obstante surgen problemas, si el TJ realmente concluyera que un tribunal alemán no cumplió el Tratado de la Unión Europea o el Tratado de Funcionamiento de la Unión Europea. La sentencia de incumplimiento es sólo una sentencia declarativa, sin embargo, los Estados miembros tienen que acatarla y ejecutarla (artículo 260 inciso $1^{\circ} \mathrm{TFUE}^{54}$ [antiguo artículo 228 inciso $\left.\left.1^{\circ} \mathrm{CE}\right]\right)^{55}$. ¿Cómo podrían hacer eso con respecto a una sentencia firme que está en contra del Derecho de la Unión? Los tribunales mismos podrían cambiar su jurisprudencia para el futuro y a través de eso seguir la sentencia del TJ. Hasta se podría pensar en un nuevo reglamento por el legislador para casos futuros que satisfagan mejor los requisitos exigidos por la sentencia de incumplimiento. A pesar de todo eso apenas sería posible una corrección de la sentencia que viola el Derecho de la Unión ${ }^{56}$. Una sentencia

sión/Italia”), Rec. 2003, I-14637, apartados 48 ss., además apartados 2 y s.

${ }^{52} \mathrm{TJ}$, asunto C-129/00 (“Comisión/Italia”), Rec. 2003, I-14637, apartado 29; allá el Tribunal se refiere a TJ, asunto 77/69 (“Comisión/Bélgica”), Rec. 1970, 237, apartado 15; mientras tanto, en 1970 el TJ se dirigió al Legislador.

${ }^{53} \mathrm{El}$ Tribunal Europeo de Derechos Humanos también considera si decisiones del Tribunal Constitucional Federal (Bundesverfassungsgericht $=$ BVerfG) están conformes con la Convención; véase, por ejemplo, el caso "Caroline", en BVerfGE [N. d. T.: Recopilación oficial de sentencias]) 101, 361; Tribunal Europeo de Derechos Humanos (Europäischer Gerichtshof für Menschenrechte), en Neue Juristische Wochenschrift (2004), p. 2.647.

${ }^{54}$ [N. d. T.: Artículo 260 inciso 1 TFUE (antiguo artículo 228 inciso $1^{\circ} \mathrm{CE}$ ): “Si el Tribunal de Justicia de la Unión Europea declarare que un Estado miembro ha incumplido una de las obligaciones que le incumben en virtud de los Tratados, dicho Estado estará obligado a adoptar las medidas necesarias para la ejecución de la sentencia del Tribunal'].

${ }^{55}$ Cremer, cit. (n. 44), Art. 228, apartado 1 ss.

${ }^{56} \mathrm{Si}$ el Estado miembro según artículo 260 inciso $1^{\circ}$ TFUE (antiguo artículo 228 inciso $1^{\circ} \mathrm{CE}$ ) está obligado a revocar la sentencia ya podría ser dudoso porque la sentencia declaratoria solamente produce efecto ex nunc [véase: BREUER, cit. (n. 47), pp. 200 
firme no se puede revocar simplemente en el Derecho alemán. No hay una norma parecida al $\$ 359 \mathrm{~N}^{\circ} 6$ Strafprozessordnung $(\mathrm{StPO}=$ Código Procesal Penal) o $\$ 580$ No 8 Zivilprozessordnung (ZPO = Código Procesal Civil $)^{57}$ (para Derecho procesal administrativo: $₫ 580$ № 8 ZPO junto con $₫ 153$ inciso $1^{\circ} \mathrm{VwGO}$ ), según los cuales la reanudación del proceso es admisible, si el Tribunal Europeo de Derechos Humanos declaró una infracción del CEDH o de uno de sus protocolos y la sentencia se fundó en ello precisamente. Como máximo, se podría pensar en una aplicación análoga de estas normas ${ }^{58}$, sin embargo, esto no debería ser compatible con la interpretación del $\$ 79$ Bundesverfassungsgerichtsgesetz (BVerfGG = Ley sobre el Tribunal Constitucional), el cual determina que en caso de una (interpretación de una) norma anticonstitucional la reanudación del proceso solamente es posible si se trata de una sentencia firme penal que se fundó en esta norma anticonstitucional ${ }^{59}$. Eso manifiesta la importante función que tiene la extensión de la responsabilidad del Estado a decisiones por el Poder Judicial en el sistema de protección jurídica del Derecho de la Unión. Si el TJ verifica el incumplimiento por un tribunal de última instancia de un Estado miembro, este Estado puede cumplir sus obligaciones del artículo 260 inciso $1^{\circ}$ TFUE (antiguo artículo 228 inciso $1^{\circ} \mathrm{CE}$ ) a través de la corrección de los resultados de la sentencia que violó el ordenamiento jurídico de la Unión por medio de la concesión de indemnización a los afectados, basado en la decisión "Köbler"60.

En el caso de "Comisión/Italia", entretanto, no se opinó que había un incumplimiento por el Poder Judicial sino que se consideró como responsable el legislador. La Comisión misma ya demandó que el TJ declare que el Estado

y 201]. Si existe o no un efecto ex nunc está discutido en la literatura, véase: CREMER, cit. (n. 44), Art. 228, apartado 6. A favor de una obligación del Estado miembro para corregir una sentencia con efecto de cosa juzgada: MeIER, cit. (n. 47), p. 14; según STORR, cit. (n. 35), p. 548, no es posible una corrección de sentencias incorrectas que produjeron efecto de cosa juzgada; compartiendo esta opinón Sellmann, Christian AugsBerg, Steffen, Entwicklungstendenzen des Vorlageverfahrens nach Art. 234 EGV, en Die Öffentliche Verwaltung, 59 (2006) 13, p. 540.

${ }^{57}$ Para otros detalles sobre la nueva razón de restitución del $₫ 580$ № 8 ZPO (que entró en vigor el 31.12.2006), véase: BRAUN, Johann, Restitutionsklage wegen Verletzung der Europäischen Menschenrechtskonvention en, Neue Juristische Wochenschrift, 60 (2007) 23, pp. 1620 ss.

${ }^{58}$ MeIER, cit. (n. 47), pp. 14 s., está a favor de admitir una acción de restitución ( $\$$ $580 \mathrm{ZPO})$.

${ }^{59}$ Una objeción basada en $₫ 79$ BVerfGG se estima como no considerable a causa del Derecho comunitario por MEIER, cit. (n. 47), p. 14.

${ }^{60} \mathrm{El}$ abogado general Geelhoed también indica que existe este derecho a exigir responsabilidad, en sus conclusiones sobre el asunto C-129/00 (Comisión/Italia), Rec. 2003, I-14637, apartado 66. 
italiano había incumplido las obligaciones del Tratado de la Comunidad Europea por mantener la norma en cuestión en su ordenamiento jurídico, la que no era compatible con los principios del Derecho comunitario por su interpretación y aplicación por la administración y los tribunales. Este punto de vista también lo sostuvieron el abogado general y el Tribunal quienes dijeron que el legislador infraccionaba sus obligaciones del Tratado de la Comunidad Europea porque no había corregido las disposiciones nacionales en cuestión, las que en realidad habían hecho posible la práctica jurídica que estaba en contra del Derecho comunitario ${ }^{61}$.

¿Cómo se puede explicar este "rodeo" ("Haltern") donde se culpa al legislador ? ${ }^{62}$ En cuanto a lo dicho por la Comisión, cuya demanda se dirigió contra una omisión del legislador italiano, este modo de proceder combina con la estrategia practicada en el pasado de no usar directamente sentencias judiciales como objeto de un recurso por incumplimiento. ${ }^{63}$ Es mucho más importante que también el TJ ve al legislador como punto de partida para un incumplimiento. Hay tres posibles explicaciones para esto, primero es posible que el Tribunal solamente quería advertir a los tribunales de los Estados miembros que tendrían que contar con una sentencia declaratoria según artículo 260 inciso $1^{\circ}$ TFUE (antiguo artículo 228 inciso $1^{\circ} \mathrm{CE}$ ) en el próximo caso. Luego se puede asumir, que se tomó el rodeo por el legislador para no atacar la jurisprudencia nacional tan directamente, después de todo, el TJ necesita tribunales dispuestos a cooperar, que implementen los principios del Derecho de la Unión y que se pongan en diálogo con el TJ a través de las cuestiones prejudiciales. Según esto, el TJ usó la estrategia de no molestar a los tribunales de los Estados Miembros ${ }^{64}$. Mas probable es sin embargo que el TJ considerara el significado de la cosa juzgada para la seguridad jurídica y para la formación del ordenamiento jurídico comunitario respectivamente del ordenamiento jurídico de la Unión ${ }^{65}$. Por ende desapareció la jurisprudencia nacional del foco directo del artículo 258 TFUE (antiguo artículo $226 \mathrm{CE}$ ). Por tomar el rodeo por la legislación el TJ evitó declarar que un tribunal había incumplido el Tratado de la Comunidad Europea y evitó

${ }^{61}$ TJ, asunto C-129/00 (Comisión/Italia), Rec. 2003, I-14637, apartados 31 ss., 41; además Abogado General Geelhoed, conclusiones en el asunto C-129/00 ("Comisión/Italia"), Rec. 2003, I-14637, apartados 101 ss., 116 y s.

${ }^{62}$ Véase: Haltern, cit. (n. 47), p. 330: "Este rodeo primero por lo menos parece raro, en el peor caso sorprendente" ("Dieser Umweg erscheint zunächst bestenfalls seltsam, schlechtestenfalls befremdlich”).

${ }^{63}$ Sobre esto también BREUER, cit. (n. 47), p. 200.

${ }^{64}$ Haltern, cit. (n. 47), pp. 332 s.; Haltern, Ulrich, Europarecht (Tübingen, Mohr Siebeck, 2005), pp. 354 s.; véase también: KomÁreK, cit. (n. 35), pp. 25 s.

${ }^{65}$ Véase, más arriba, II. 
cuestionar la cosa juzgada de una sentencia judicial. Pocas semanas después de la decisión "Köbler" no hubiera sido aceptable otro mensaje para los ordenamientos jurídicos nacionales y la Comunidad Europea.

\section{Quebranto de la firmeza de las resoluciones administrativas judicialmente confirmadas.}

El siguiente caso trata sobre la corrección realizada por el Derecho de la Unión de una resolución administrativa firme que fue confirmada por un tribunal con efectos de cosa juzgada (caso "Kühne \& Heitz"). La firmeza de la resolución administrativa sirve a un objetivo parecido al de la cosa juzgada, y este es el garantizar de la seguridad jurídica. La dogmática alemana distingue entre firmeza formal y material al igual que lo ocurrido con la cosa juzgada ${ }^{66}$.

La firmeza de las resoluciones administrativas está limitada de muchas formas distintas por el Derecho de la Unión ${ }^{67}$, un ejemplo de ello es que es más fácil revocar una resolución en caso que se trate de decisiones sobre beneficios otorgados por los Estados que están en contra del Derecho de la Unión (artículos 107 y s. TFUE [antiguo artículo 87 s. CE]) ${ }^{68}$. Eso demuestra el nivel de influencia del Derecho de la Unión en la autonomía procesal de los Estados miembros y como se europeíza el Derecho procesal administrativo. Sobre todo $₫ 48$ Verwaltungsverfahrensgesetz $(\mathrm{VwVfG}=$

${ }^{66}$ Para más detalles sobre el concepto de la firmeza y sobre las paralelas a la cosa juzgada consúltese: MAUrer, Hartmut, Allgemeines Verwaltungsrecht (16 a edición, München, Beck, 2006) $\$ 11$, apartados 1 ss.

${ }^{67}$ Sobre esto véase: HATJE, Armin, Die Rechtskraft und ihre Durchbrechungsmöglichkeiten im Lichte des Gemeinschaftsrechts, en: HoloubeK, Michael - LANG, Michael (editores), Das EuGH-Verfahren in Steuersachen (Wien, Linde, 2000), pp. 137 ss.; Schmidt-Assmann, Eberhard, Die Europäisierung des Verwaltungsverfahrensrechts, en: Festgabe 50 Jahre Bundesverwaltungsgericht (Köln y otras, Heymanns, 2003), pp. 490 ss.; Ротасs, Michael, Gemeinschaftsrecht und Bestandskraft staatlicher Verwaltungsakte, en Internationale Gemeinschaft und Menschenrechte. Festschrift für Georg Ress (Köln y otras, Heymanns, 2005), pp. 729 ss.; GärdITz, Klaus Ferdinand, Die Bestandskraft gemeinschaftsrechtswidriger Verwaltungsakte zwischen Kasuistik und Systembildung en, Nordrhein-Westfälische Verwaltungsblätter, 20 (2006) 12, pp. 441 ss.; RENNERT, Klaus, Bestandskraft rechtswidriger Verwaltungsakte und Gemeinschaftsrecht, en Deutsches Verwaltungsblatt, 122 (2007) 7, pp. 400 ss.

${ }^{68}$ Véase, sobre todo, la jurisprudencia "Alcan" del TJ, asunto C-24/95 ("Alcan II”) Rec. 1997, I-1591 y BVerwGE [N. d. T.: Recopilación oficial de sentencias del BverwG] 106, p. 328; además BverwGE, 92, p. 81; más detallado: Suerbaum, Joachim, Die Europäisierung des nationalen Verwaltungsverfahrensrechts am Beispiel der Rückabwicklung gemeinschaftsrechtswidriger staatlicher Beihilfen en, Verwaltungsarchiv, 91 (2000) 2, pp. 169 ss.; Scheuing, Dieter Helmut, Europäisierung des Verwaltungsrechts en, Die Verwaltung, 34 (2001) 1, pp. 107 ss. 
Ley de Procedimiento Administrativo), según el cual las resoluciones administrativas ilegales que son firmes y beneficiosas para los administrados pueden ser revocadas bajos ciertas circunstancias, no puede ser aplicado o por lo menos está superpuesto por el Derecho de la Unión y tiene que ser interpretado conforme a este. Esto concierne, por ejemplo, a la disposición sobre la protección de la confianza legitima en el $\$ 48$ inciso $2^{\circ} \mathrm{VwVfG}$. Además, la administración alemana está obligada a revocar una decisión de ayuda, donde esta misma decisión esté en contra del Derecho de la Unión y no hay espacio para discrecionalidad sobre la revocación como lo tendría en caso que se aplique el $\S 48$ inciso $1^{\circ} \mathrm{VwVfG}$. El afectado tampoco puede alegar un plazo de revocación como lo existe en el $₫ 48$ inciso $4^{\circ} \mathrm{VwVfG}$. Con todo esto se posibilita una revocación de resoluciones administrativas firmes lo cual no ocurriría bajo el imperio del Derecho alemán de esa forma. La firmeza de las resoluciones administrativas queda en segundo lugar frente al principio de efectividad ("effet utile") del Derecho de la Unión.

Otro paso en la misma dirección fue la sentencia Ciola, donde no se vio la pregunta sobre los requisitos con lo que se puede revocar una resolución administrativa, el tema del procedimiento por cuestiones prejudiciales era más bien el efecto vinculante de una resolución administrativa firme que infraccionó el Derecho comunitario, esto después de la adhesión de Austria a la Unión Europea. Refiriéndose al principio de la primacía del Derecho comunitario el TJ decidió que era inaplicable esta resolución administrativa individual-concreto y firme con respecto a la determinación si una pena pecuniaria era lícita o no ${ }^{69}$. En su resultado esta decisión seguramente era correcta, entretanto la fundamentación del TJ causó dudas, pues pareció según lo dicho se debilitó la firmeza de las resoluciones administrativas nacionales en contra del Derecho comunitario ${ }^{70}$.

El caso "Kühne \& Heitz" vio el destino de una resolución sobre un reembolso cuya legitimidad ya había sido confirmada por un tribunal con efectos de cosa juzgada. Este tribunal (neerlandés) no interpretó el Derecho comunitario correctamente en su decisión, y aunque no existió un recurso contra la sentencia no planteó una cuestión prejudicial ante el TJ según artículo 267 inciso $3^{\circ}$ TFUE (antiguo artículo 234 inciso $3^{\circ} \mathrm{CE}$ ). Cuando después el TJ interpretó las normas en cuestión en un procedimiento posterior de una manera diferente que el tribunal neerlandés, el afectado solicitó de inmediato al pago del monto que había reembolsado injustamente. La autoridad competente neerlandesa rechazó la solicitud. El tribunal de Países

${ }^{69} \mathrm{TJ}$, asunto C-224/97 (“Ciola”), Rec. 1999, I-2517, apartados 25 ss.

${ }^{70}$ Sobre esto Potacs, cit. (n. 25), pp. 595 ss.; GundeL, Jörg, Bootsliegeplatz-Privilegien für Einheimische: Verstoßgegen die Dienstleistungsfreiheit und Durchbrechung der nationalen Bestandskraft-Regeln? en, Europarecht, 34 (1999) 6, pp. 786 ss. 
Bajos que entonces tenía que ver el asunto quería saber la opinión del TJ, si el Derecho comunitario obliga a una autoridad revocar una resolución firme en un caso como este. En la sentencia el TJ, distinto a lo que se podía esperar después de la decisión "Ciola", no sostuvo la opinión que la firmeza tenía que ceder a la primacía del Derecho comunitario si no que realzó que la firmeza contribuía a la seguridad jurídica y por ende el Derecho comunitario no exigía una obligación básica de una autoridad administrativa de revocar una resolución administrativa firme ${ }^{71}$.

Mientras tanto, basado en el artículo 10 CE (actualmente artículo 4 inciso $3^{\circ}$ Tratado de la Unión Europea ${ }^{72}$ : principio de la cooperación leal) el TJ partió de la existencia de una obligación de la autoridad de revisar una decisión administrativa firme dado el caso, que se cumplían los cuatro requisitos siguientes: $i$ ) El Derecho nacional reconoce al órgano administrativo la posibilidad de reconsiderar la resolución firme controvertida en el litigio principal; ii) La firmeza se adquirió porque se pronunció una sentencia de un órgano jurisdiccional nacional cuyas decisiones no son susceptibles de ulterior recurso judicial; iii) La sentencia se basaba en una interpretación del Derecho comunitario que, a la vista de una sentencia posterior del Tribunal de Justicia, era errónea y que se había adoptado sin someter la cuestión ante este último, con carácter prejudicial, conforme a los requisitos previstos en el artículo 234 inciso $3^{\circ} \mathrm{CE}$ (actualmente artículo 267 inciso $3^{\circ} \mathrm{TFUE}$ ); y iv) El afectado se dirigió al órgano administrativo inmediatamente después de haber tenido conocimiento de esta sentencia del Tribunal de Justicia. ${ }^{73}$. La autoridad tenía que decidir según los resultados de su revisión, en qué medida estaba obligada a retirar la decisión sin lesionar derechos de terceros ${ }^{74}$. En el

${ }^{71} \mathrm{TJ}$, asunto C-453/00 (“Kühne \& Heitz”), Rec. 2004, I-837, apartado 24.

${ }^{72}$ [N. d. T.: Artículo 4 inciso $3^{\circ}$ Tratado de la Unión Europea (que en sustancia reemplaza el antiguo artículo $10 \mathrm{CE}$ ): "Conforme al principio de cooperación leal, la Unión y los Estados miembros se respetarán y asistirán mutuamente en el cumplimiento de las misiones derivadas de los Tratados./ Los Estados miembros adoptarán todas las medidas generales o particulares apropiadas para asegurar el cumplimiento de las obligaciones derivadas de los Tratados o resultantes de los actos de las instituciones de la Unión./ Los Estados miembros ayudarán a la Unión en el cumplimiento de su misión y se abstendrán de toda medida que pueda poner en peligro la consecución de los objetivos de la Unión"].

${ }^{73} \mathrm{TJ}$, asunto C-453/00 ("Kühne \& Heitz"), Rec. 2004, I-837, apartados 26 ss.

${ }^{74} \mathrm{TJ}$, asunto C-453/00 (“Kühne \& Heitz”), Rec. 2004, I-837, apartado 27. Sobre la pregunta si existe solamente una obligación a revisar o también una para revocar consúltese, por ejemplo, Britz, Gabriele - Richter, Tobias, Die Aufhebung eines gemeinschaftsrechtswidrigen nicht begünstigenden Verwaltungsakts en, Juristische Schulung, 45 (2005) 3, pp. 199 s., 201 s.; LindNER, Josef Franz, "Anmerkung”, en Bayerische Verwaltungsblätter, 135 (2004) 19, p. 591. 
Derecho alemán los $₫ 48$ inciso $1^{\circ}$ frase $1^{\mathrm{a}}$ o $₫ 51 \mathrm{VwVfG}^{75}$ pueden ser base jurídica para una incorporación de las exigencias de "Kühne \& Heitz"76.

Estos requisitos de Derecho comunitario respectivamente de Derecho de la Unión para una revisión están formulados de una forma general, pero se refieren exactamente a la situación que realmente era la base del caso "Kühne \& Heitz". Hasta qué punto estos criterios son aplicables a otros casos, si son taxativos o si la jurisprudencia futura los corregirá, hasta ahora esto no es previsible ${ }^{77}$. Para Skouris, el presidente del TJ, de toda forma son requisitos excepcionales $^{78}$, en la sentencia posteriormente dictada “i-21 y Arcor", en la que Skouris participó como juez y la que de nuevo trató la posibilidad de revocar resoluciones administrativas firmes, de hecho no se refirió a "Kühne \& Heitz". El Tribunal enfatizó que "Kühne \& Heitz" era "totalmente" diferente al caso "i-21 y Arcor", donde el afectado precisamente no había recurrido contra la primera decisión ilegítima ${ }^{79}$. En "i-21 y Arcor", el Bundesverwaltungsgericht $(\mathrm{BVerwG}=$ Tribunal Contencioso-Administrativo Federal) planteó entre otras cosas la cuestión prejudicial ante del TJ, sobre si existía

${ }^{75}$ [N. d. T.: $\$ 48$ inciso $1^{\circ}$ frase $1^{a}$ VwVfG: "Una resolución administrativa ilegitima puede ser revocada en total o en parte con efecto para el futuro o para el pasado, aun cuando se volvió inapelable". El párrafo trata además la protección de la confianza y condiciones que se oponen a la revocación. El $\$ 51 \mathrm{VwVfG}$ trata la reanudación del procedimiento]. Para saber más véase, por ejemplo: MAURER, Hartmut, Introducción al Derecho administrativo alemán (Bogotá, Editorial Universidad Santo Tomás, 2008) 123 pp.

${ }^{76}$ Más detalles en: Lenze, Anne, Die Bestandskraft von Verwaltungsakten nach der Rechtsprechung des EuGH, en Verwaltungsarchiv, 97 (2006) 1, pp. 51 ss.; LINDNER, cit. (n. 74), p. 592; además BRITZ - Richter, cit. (n. 74), pp. 200 ss., pero que están en contra de una aplicación del $\$ 51 \mathrm{VwVfG}$ (más detallado sobre esto en lo siguiente).

${ }^{77}$ BRITZ - RichteR, cit. (n. 74), p. 199. En asunto C-2/06 (“Kempter”) se trata del aclaramiento de contenido y alcance de la sentencia "Kühne \& Heitz"; pero hasta ahora solamente existen las conclusiones de abogado general Bot del 24.4.2007 (Revisado: 20.7.2007).

${ }^{78}$ SkOURIs, Vassilios, Rechtsfolgen der Verletzung des Europäischen Gemeinschaftsrechts durch oberste Gerichte der Mitgliedstaaten, en Für Sicherheit, für Europa. Festschrift für Volkmar Götz zum 70. Geburtstag (Göttingen, Vandenhoeck \& Ruprecht, 2005), p. 236.

${ }^{79} \mathrm{TJ}$, asuntos acumulados C-392/04 y C-422/04 (“i-21 y Arcor”), Rec. 2006, I-8559, apartados 53 s. El abogado general Ruiz-Jarabo Colomer, en sus conclusiones sobre los asuntos acumulados C-392/04 y C-422/04 (“i-21 y Arcor”), Rec. 2006, I-8559, no fundó su voto en "Kühne \& Heitz", sino en principios generales (véanse los apartados 65 ss., 94 ss.); según él, la "doctrina” de "Kühne \& Heitz": "conduce a una vía muerta” (apartado 3). Sobre la sentencia "i-21 y Arcor”, véase, por ejemplo: Ruffert, Matthias, “Anmerkung”, en JuristenZeitung, 62 (2007) 8, pp. 407 ss.; LuDwigs, Markus, Die Arcor-Entscheidung des EuGH: Ein Beitrag zur Stärkung der mitgliedstaatlichen Verfahrensautonomie, en Neue Zeitschrift für Verwaltungsrecht, 26 (2007) 5, pp. 549 ss. 
una obligación por el Derecho comunitario de revocar una notificación de una tarifa no impugnada, que infringía una norma de la directiva sobre concesiones de licencias (97/13/CE), en el caso que el Derecho nacional permita la revocación, pero no la exija ${ }^{80}$. La base jurídica para la revocación según Derecho alemán en ese caso era el $\$ 48$ inciso $1^{\circ}$ frase $1^{a}$ VwVfG. En el razonamiento de la decisión, el TJ acentuó especialmente la autonomía procesal de los Estados miembros y no declaró una obligación de revocar, considerando también el principio de la efectividad. El TJ estimó como posible que tal obligación se derivaba del principio de equivalencia, pero lo dejó al Bundesverwaltungsgericht decidir sobre aquel punto ${ }^{81}$.

Considerando el caso "Kühne \& Heitz" uno se pregunta qué efectos tiene esta decisión del TJ para la cosa juzgada de sentencias judiciales nacionales. Aunque el TJ no exigió la revocación o corrección de la sentencia judicial nacional misma, sino solamente opinó sobre la revisión de una resolución administrativa firme (y confirmado por un tribunal) por la misma administración, el abogado general Léger aclaró en sus conclusiones que el Derecho comunitario puede primar sobre la cosa juzgada nacional. Acentuó que el principio de la primacía del Derecho comunitario era válido para la administración con la misma fuerza, independiente de la pregunta si el asunto trataba una sentencia que produce efecto de la cosa juzgada o no. Además se refirió a sus conclusiones en el caso "Köbler", donde había explicado que una norma nacional como aquella sobre la observancia de la cosa juzgada no puede ser contraria al principio de la primacía del Derecho comunitario con el fin de hacer fracasar una demanda de responsabilidad del Estado ${ }^{82}$. Y el abogado general Geelhoed calificó (sosteniendo el mismo razonamiento que Léger en el caso "Köbler") el caso "Kühne \& Heitz" en la misma línea como "Köbler" y "Comisión/Italia", por el tema de incumplimiento del Derecho comunitario por la jurisprudencia nacional ${ }^{83}$. Es interesante que el

${ }^{80}$ Sobre la cuestión planteada: BVerwGE, 121, p. 226.

${ }^{81} \mathrm{TJ}$, asuntos acumulados. C-392/04 y C-422/04 (“i-21” y “Arcor”), Rec. 2006, I-8559, apartados 56 ss. El Tribunal Contencioso-Administrativo Federal decidió, como consecuencia de no existir un derecho a la retirada de la notificación de tasa/tarifa, véanse las sentencias del Tribunal Contencioso-Administrativo Federal (Bundesverwaltungsgericht) del 17 de enero de 2007, $\mathrm{N}^{\circ}$ de ref. 6 C 32.06, en Neue Zeitschrift für Verwaltungsrecht (2007), 709) y $\mathrm{N}^{\circ}$ de ref. 6 C 33.06.

${ }^{82}$ Véanse las conclusiones del abogado general Léger sobre el asunto C-453/00 (“Kühne \& Heitz”), Rec. 2004, I-837, apartados 66 con comentario 56; y las del mismo abogado, en el asunto C-224/01 (“Köbler”), Rec. 2003, I-10239, apartado 106.

${ }^{83}$ Conclusiones del abogado general Geelhoed en el asunto C-129/00 ("Comisión/ Italia”), Rec. 2003, I-14637, apartados 2 s.; del abogado general Léger, en el asunto C-224/01 ("Köbler"), Rec. 2003, I-10239, apartado 3. Que en "Kühne \& Heitz" una de las cosas especiales fue la sentencia que produjo efecto de cosa juzgada, eso hubo de 
TJ en "Kühne \& Heitz", contrario a lo hecho por el abogado general Léger, no se ocupó del tema de la cosa juzgada de la sentencia, sino que solamente mencionó la sentencia del tribunal de última instancia como un mero elemento descriptivo del caso ${ }^{84}$.

Cuando uno se abstrae de las formulaciones indeterminadas con respecto a la cosa juzgada por el TJ, sigue existiendo la pregunta si "Kühne \& Heitz" en su resultado realmente cuestiona la cosa juzgada. El tribunal planteando la cuestión prejudicial estimó que según el Derecho neerlandés la administración estaba autorizada sin problema alguno a revocar la notificación firme ${ }^{85}$. Parece que la cosa juzgada no estaba en contra de eso ${ }^{86}$. ¿Qué efecto tiene entonces el hecho de que una resolución administrativa firme fue confirmado por un tribunal administrativo con efecto de cosa juzgada para la posibilidad de su revocación según Derecho alemán? En cuanto a la revocación de tal resolución administrativa, es decir una situación como en el caso "Kühne \& Heitz", según el Derecho administrativo alemán hay que distinguir entre la reanudación según $\$ 51 \mathrm{VwVfG}$ y la reanudación en un sentido más amplio (basado en los $\$ \$ 8 \mathrm{~s}$. VwVfG, compárese $\$ 51$ inciso $\left.5^{\circ} \mathrm{VwVfG}\right)^{87}$.

Primero en cuanto a $₫ 51 \mathrm{VwVfG}$, si se cumplen los requisitos para la reanudación, la autoridad decide de nuevo sobre el asunto (segunda notificación). Si la autoridad promulga una segunda notificación negativa el afectado puede atacarla judicialmente. En la jurisprudencia y la literatura se reconoce que no se opone a tal acción el hecho que se desestime con efecto de cosa juzgada un recurso contra la primera notificación ${ }^{88}$. Pero en un caso como en "Kühne \& Heitz" no sería aplicable el $\$ 51$ VwVfG conforme a la dogmática presente del Derecho administrativo alemán ${ }^{89}$. Especialmente el dictado de una sentencia del $\mathrm{TJ}$, por el cual se manifestaría que la interpreta-

ser acentuado, además, por el abogado general Ruiz-Jarabo Colomer, en sus conclusiones sobrte el asuntos acumulados C-392/04 u. C-422/04 (“i-21" y “Arcor"), Rec. 2006, I-8559, apartado 112 con comentario 84 .

${ }^{84}$ TJ, asunto C-453/00 (“Kühne \& Heitz"), Rec. 2004, I-837, apartados 22 ss.

${ }^{85} \mathrm{TJ}$, asunto C-453/00 (“Kühne \& Heitz"), Rec. 2004, I-837, apartados 12, 25 y s.

${ }^{86}$ Véase también: Ruffert, Matthias, Anmerkung zum Urteil des EuGH $v$. 16.3.2006, Rs. C-234/04 (“Kapferer"), en JuristenZeitung, 61 (2006) 18, p. 905.

${ }^{87}$ Véase sobre esto: MAURER, cit. (n. 66), $\$ 11$, apartados 54 ss.; RUFFERT, Matthias, Wiederaufgreifen des Verfahrens, en ERICHSEN, Hans-Uwe - EHLERs, Dirk (editores), Allgemeines Verwaltungsrecht (13ª edición, Berlin, De Gruyter, 2006), §25.

${ }^{88}$ BVerwGE 70, pp. 111 s.; 82, pp. 274 s.; RufFERT, cit. (n. 87), \$25, apartado 11; Clausing, cit. (n. 19), $\$ 121$ VwGO, apartado 78; Sachs, Michael, “ $\$ 51$ ”, en STELKens, Paul - Bonk, Heinz Joachim - SACHS, Michael, Verwaltungsverfahrensgesetz (6ª edición, München, Beck, 2001), \$51 VwVfG, apartados 83 ss.

${ }^{89}$ Véase sobre esto: Britz - Richter, cit. (n. 74), pp. 200 s.; Rennert, cit. (n. 67), p. 408. 
ción del tribunal nacional era contra el Derecho de la Unión (tercer requisito de "Kühne \& Heitz"), por tanto no sería un cambio de la base jurídica en el sentido del $\$ 51$ inciso $1 \mathrm{~N}^{\circ} 1 \mathrm{VwVfG}$. Un cambio de la jurisprudencia de los tribunales supremos generalmente no se califica como un cambio de la base jurídica ${ }^{90}$. Si se implementan los resultados de "Kühne \& Heitz" al Derecho alemán sin interpretar el $\$ 51$ inciso $1^{\circ} \mathrm{VwVfG}$ extensivamente ${ }^{91}$, se tendría que aplicar el $\S 48$ inciso $1^{\circ}$ frase $1^{a} \mathrm{VwVfG}$. Pero con respecto a ese párrafo también se sostiene la opinión que no se excluye una revocación según $₫ 48 \mathrm{VwVfG}$ por la cosa juzgada de una sentencia que desestimó un recurso contra la primera notificación como no fundado. Entonces se tiene que tomar en cuenta lo siguiente, el Derecho alemán permite la revocación de resoluciones administrativas que fueron confirmados judicialmente por un tribunal anteriormente ${ }^{92}$. Considerando eso, no se debería hablar de un quebranto de la cosa juzgada, sino mejor de un "quebranto de la firmeza" ("Durchbrechung der Bestandskraft") por el caso "Kühne \& Heitz"93. Mientras tanto, la dirección de la sentencia está en la misma línea que en ]"Köbler" y "Comisión/Italia". Se quiere motivar a los tribunales presentar más cuestiones prejudiciales. El TJ acentuó enérgicamente en "Kühne \& Heitz" que el tribunal neerlandés omitió plantear una cuestión prejudicial, contrario a su obligación según artículo 234 inciso $3^{\circ} \mathrm{CE}$ (actualmente artículo 267 inciso $3^{\circ}$ TFUE $)^{94}$.

\section{5. ¿Quebranto de la cosa juzgada de sentencias de los Estados miembros?}

Gracias a la sentencia "Kühne \& Heitz" se podía pensar que el paso si-

${ }^{90}$ Maurer, cit. (n. 66) $₫ 11$, apartado 58; Kopp, Ferdinand O. - Ramsauer, Ulrich, Verwaltungsverfahrensgesetz ( $9^{a}$ edición, München, Beck, 2005), §51 VwVfG, apartado 30 .

${ }^{91} \mathrm{~A}$ favor de la aplicación del $₫ 51$ VwVfG están: LeNZE, cit. (n. 76), pp. 56 ss.; y LINDNER, cit. (n. 74), p. 592.

${ }^{92}$ Véase: Kopp - Schenke, cit. (n. 1), $\$ 121$ VwGO, apartado 13; SaCHS, cit. (n. 88), $₫ 48$ VwVfG, apartado 61; RenNeRT, Klaus, Kommentierung von $\$ 121$ VwGO, en Eyermann, Erich, Verwaltungsgerichtsordnung. Kommentar (12 edición, München, Beck, 2006), §121 VwGO, apartado 27; véase también: Kopp, Ferdinand O. - Kopp, Ferdinand J., Grenzen der Rechtskraftwirkung von Urteilen aufgrund von Anfechtungsklagen, en Neue Zeitschrift für Verwaltungsrecht, 13 (1994) 1, p. 4.

${ }^{93}$ Véanse: Кокотт, Juliane - Henze, Thomas - Sовотта, Christoph, Die Pflicht zur Vorlage an den Europäischen Gerichtshof und die Folgen ihrer Verletzung, en JuristenZeitung, 61 (2006) 13, pp. 639 ss.; SChmidt-Westphal, Oliver - SANDER, Dirk, Anmerkung zum Urteil des EuGH v. 16.3.2006, Rs. C-234/04 ("Kapferer")", en Europäische Zeitschrift für Wirtschaftsrecht, 17 (2006) 8, p. 243; sostiene otra opinon: KENNTNER, cit. (n. 5), p. 237.

${ }^{94} \mathrm{TJ}$, asunto C-453/00 (“Kühne \& Heitz”), Rec. 2004, I-837, apartados 26, 28 (3 $3^{\text {er }}$ requisito). 
guiente era cuestionar al efecto de cosa juzgada de las sentencias nacionales, en ese mismo sentido es que un tribunal austríaco presentó una cuestión prejudicial según el artículo $234 \mathrm{CE}$ (actualmente artículo 267 TFUE) donde se le pidió directamente la declaración al TJ en el llamado caso "Kapferer". Los Estados miembros calificaron el tema como de alta relevancia, pues participaron nueve Estados en la vista pública del caso.

Un "test" ideal para la solución de un conflicto directo entre la cosa juzgada y los principios de la primacía y de la efectividad del Derecho de la Unión podría ser donde un Estado tenga que pagar una indemnización por un tribunal de última instancia que viole de manera manifiesta el Derecho de la Unión y que omita además, contrario a artículo 267 inciso $3^{\circ}$ TFUE (antiguo artículo 234 inciso $3^{\circ} \mathrm{CE}$ ), plantear una cuestión prejudicial ante el TJ. La situación del caso "Kapferer" era menos problemática y por ende menos adecuado para aclarar esta pregunta fundamental. Un tribunal de primera instancia decidió que tenía competencia sobre un caso de protección al consumidor, lo cual podía no ser conforme con el Derecho comunitario, luego el tribunal de segunda instancia que planteó la cuestión prejudicial se preguntó, refiriéndose a "Kühne \& Heitz", si según Derecho comunitario estaba obligado a corregir esta decisión de primera instancia, la que mientras tanto produjo efecto de cosa juzgada porque ninguna de las partes recurrió contra esta decisión. Según Derecho procesal civil austríaco normalmente no estaba permitida esta corrección, la respuesta del TJ era clara a la primera vista y acentuó especialmente el significado del principio de la cosa juzgada ${ }^{95}$. Al mismo tiempo aclaró que el Derecho comunitario no obligaba a un tribunal nacional a no considerar y aplicar normas procesales nacionales en cuya base una decisión (que es en contra del Derecho comunitario) iba a producir efecto de cosa juzgada, lo mismo que ya había sostenido anteriormente en el caso "Eco Swiss", al que en la misma sentencia se refirió ${ }^{96}$.

El abogado general Tizzano propuso restringir "Kühne \& Heitz" solo a los casos de resoluciones administrativas firmes y no aplicarlo a sentencias que produjeron cosa juzgada, y examinó por mera precaución los cuatro requisitos de "Kühne \& Heitz", de los cuales no se cumplió ninguno ${ }^{97}$. Sin embargo,

${ }^{95}$ TJ, asunto C-234/04 ("Kapferer"), Rec. 2006, I-2585, apartado 20; las conclusiones del abogado general Tizzano, en el asunto C-234/04 ("Kapferer"), Rec. 2006, I-2585, apartado 22.

${ }^{96} \mathrm{TJ}$, asunto C-234/04 (“Kapferer”), Rec. 2006, I-2585, apartado 21, con referencia a asunto C-126/97 ("Eco Swiss"), Rec. 1999, I-3055, apartados 46 s.; conclusiones del abogado general Tizzano, en el asunto C-234/04 (“Kapferer”), Rec. 2006, I-2585, apartado 23.

${ }^{97}$ Conclusiones del abogado general Tizzano, en el asunto C-234/04 ("Kapferer"), Rec. 2006, I-2585, apartados 24 y s., 26 ss. 
el TJ no quería tomar postura en este punto, lo que hace difícil interpretar su decisión en el caso "Kapferer" como una negativa a la limitación por el Derecho de la Unión de la cosa juzgada. Esto dejó un vacío si es que "Kühne \& Heitz" era aplicable a decisiones judiciales: "aun suponiendo" que los principios de "Kühne $\&$ Heitz" fueran aplicables a decisiones judiciales que producen efecto de cosa juzgada, no importaría en el caso concreto porque no se cumplía el primer requisito, según el cual el órgano administrativo (o el tribunal) tiene que poder, conforme al Derecho nacional, revocar la decisión firme (o con cosa juzgada) $)^{98}$. Esto muestra al mismo tiempo que el TJ respetó la autonomía procesal nacional en "Kapferer" hasta el punto de no exigir una corrección de la decisión judicial según el ordenamiento jurídico comunitario, por lo menos en el caso que el Derecho nacional no contemple la corrección.

Según el Derecho alemán no sería posible la corrección de una decisión judicial con cosa juzgada por violación del Derecho de la Unión, salvo algunos casos especiales. Una acción de restitución según $₫ 580 \mathrm{ZPO}$ (en caso necesario verlo en relación con $\$ 153$ inciso $1^{\circ} \mathrm{VwGO}$ ) para el caso de una decisión contraria al Derecho de la Unión queda excluido por falta de razones de restitución apropiados ${ }^{99}$. Incluso si dado el caso que el TJ declararía la violación de Derecho de la Unión de una decisión judicial, no existía una razón de restitución; $\$ 359$ № 6 StPO y $\$ 580$ № 8 ZPO se refieren solamente a la $\mathrm{CEDH}^{100}$ $\$ 826 \mathrm{BGB}^{101}$ (abuso de títulos de ejecución) tampoco ayudaría ${ }^{102}$. De eso se deriva que para el Derecho procesal alemán de toda

${ }^{98} \mathrm{TJ}$, asunto C-234/04 (“Kapferer”), Rec. 2006, I-2585, apartado 23. Sobre la pregunta de la aplicabilidad de la jurisprudencia "Kühne \& Heitz" a decisiones judiciales que produjeron efecto de cosa juzgada, consúltese también: Ludwigs, Markus, Der Schutz der Rechtskraft im Gemeinschaftsrecht, Zugleich eine Anmerkung zur KapfererEntscheidung des EuGH, en Zeitschrift für Europarecht, Internationales Privatrecht und Rechtsvergleichung, 47 (2006) 5, pp. 193 s.

${ }^{99}$ Sobre esto también: Streinz, Rudolf, Anmerkung zum Urteil des EuGH v. 16.3.2006, Rs. C-234/04 (“Kapferer"), en Juristische Schulung, 46 (2006) 7, p. 639; véase, además: Reichold, Klaus, Kommentierung vor $\$ 578$ ZPO, en Thomas, Heinz Putzo, Hans, Zivilprozessordnung. Kommentar (28 edición, München, Beck, 2007); véase: $\$ 578 \mathrm{ZPO}$, apartado $1^{\circ}$ sobre no aplicar análogamente los $\$ \$ 578$ ss. ZPO, si el $\mathrm{TJ}$ sostiene otra opinión en una sentencia posterior.

${ }^{100}$ Veáse ya arriba 3.

${ }^{101}[$ N. d. T.: $\$ 826$ BGB: “Quien dolosamente causa un daño a otra persona de una manera contrario a las buenas costumbres está obligado a indemnizarle por el daño" (EIRanova Encinas, Emilio, Código Civil Alemán (Madrid, Editorial Marcial Pons, 1998) 720 pp.].

${ }^{102}$ Véase, sobre los requisitos: Sprau, Hartwig, Kommentierung von $\$ 826 B G B$, en Palandt, Otto, Bürgerliches Gesetzbuch (66ª edición, München, Beck, 2007), $\$ 826$ BGB, apartados 52 ss. 
forma el primer requisito de la decisión "Kühne \& Heitz" del principio se cumpliría nunca y que por ende "Kühne \& Heitz" ya de esta razón no sería aplicable para decisiones judiciales en contra del Derecho de la Unión.

Mientras tanto, el Tribunal de Justicia tenía otra posibilidad para opinar sobre los límites de la cosa juzgada de decisiones judiciales nacionales. En el caso "Lucchini" se obligó por una sentencia civil nacional al la República italiana a pagar una ayuda, aunque la Comisión había declarado anteriormente en una decisión firme que la ayuda estaba en contra del Mercado Común. Los tribunales civiles que vieron el asunto no consideraron la decisión de la Comisión y las autoridades competentes tampoco reclamaron su observancia. Después de pagar la ayuda la Comisión ordenó a las autoridades nacionales reivindicar la ayuda, lo cual hicieron. El beneficiario de la ayuda entonces se acogió a la cosa juzgada de la sentencia judicial civil en el procedimiento administrativo, en el cual se trató la legitimidad de la reivindicación de la ayuda. Según el artículo 2909 del Codice Civile italiano la declaración incluida a una sentencia que produjo efecto de cosa juzgada tiene efecto vinculante siempre para las partes, lo cual es ratificado por los tribunales italianos, y esto excluye todos los elementos de ataque y defensa que normalmente hubieran sido alegables en el procedimiento que ahora se cerró con cosa juzgada. En este caso concreto la interpretación habría podido decir que la decisión de la Comisión, declarando la inadmisibilidad de la ayuda, no podía ser considerada en el procedimiento administrativo. En la cuestión prejudicial el Consiglio di Stato preguntó, si sería posible y adecuado reivindicar una ayuda en contra del Derecho comunitario pese a una sentencia civil oponiéndose, la que produjo efecto de cosa juzgada. El TJ contestó afirmativamente, que el Derecho comunitario se oponía a la aplicación de una norma "que pretende consagrar el principio de autoridad de la cosa juzgada”, como el artículo 2909 del Codice Civile, cuando su aplicación impida la recuperación de una ayuda de Estado, cuya incompatibilidad con el Mercado Común ya se determinó por una decisión de la Comisión ${ }^{103}$. Con esto, el TJ por la primera vez declaró expresamente que el Derecho de la Unión limita la cosa juzgada de decisiones judiciales nacionales.

En el razonamiento de la sentencia el TJ no citó ni la decisión "Kühne \& Heitz", ni la decisión "Kapferer", por el contrario se refirió al principio de la efectividad y a su jurisprudencia en las sentencias "Simmenthal" y "Factortame I", donde resolvió el conflicto entre el principio de la efectividad del Derecho comunitario y el principio de la autonomía procesal de los Estados miembros claramente a favor de la efectividad del Derecho comunitario ${ }^{104}$.

${ }^{103}$ TJ, asunto C-119/05 ("Lucchini”), Rec. 2007, I-6199, apartado 63.

${ }_{104}$ TJ, asunto C-119/05 ("Lucchini”), Rec. 2007, I-6199, apartado 61, además 
En la decisión "Lucchini" el Tribunal aclaró que la aplicación del principio de la efectividad tenía que asegurar distribución de competencias entre la Comisión y los tribunales de los Estados miembros para el sector del Derecho de ayudas, donde solo la Comisión es competente para determinar la compatibilidad de una ayuda con el Mercado Común y no los tribunales nacionales, estos tampoco son competentes para determinar la invalidez de actos comunitarios como por ejemplo de una decisión de la Comisión ${ }^{105}$. En el caso concreto la interpretación del artículo 2909 del Codice Civile podía generar efectos para una decisión de un tribunal nacional (aquí el tribunal civil que condenó a las autoridades italianas pagar la ayuda en el primer caso) que excedían los límites de su competencia. Esto impediría la aplicación de Derecho comunitario porque de esta forma se haría imposible reivindicar una ayuda que está en contra del mismo. Por ende el TJ lo declaró como completamente opuesto a la interpretación del artículo 2909 del Codice Civile italiano ${ }^{106}$.

Al final la decisión en el caso "Lucchini" complementa la jurisprudencia del TJ sobre la reivindicación de ayudas contrarias al Derecho de la Unión que se concedieron por resoluciónes firmes por las autoridades nacionales ${ }^{107}$. Entretanto, el caso concreto se basó en una situación atípica, no se opuso la firmeza de la resolución de autorización, sino una sentencia civil con efecto de cosa juzgada, por eso para el TJ no había otra posibilidad que cambiar la cosa juzgada para darle mayor efectividad al Derecho de ayudas comunitario. Diferente a los casos mencionados arriba (en 2.4) "Köbler", "Traghetti", "Comisión/Italia" y "Kühne \& Heitz" el TJ en "Lucchini" no reaccionó a un desacato de la obligación de los tribunales nacionales a plantear cuestiones prejudiciales, sino a un desacato del Derecho de ayudas que era claro en este punto y de una decisión de la Comisión. No se puede ver como establecido que la cosa juzgada de decisiones judiciales nacionales tendría que ceder generalmente a la primacía y la efectividad del

apartados 59 s. Véase: TJ, asunto 106/77 (“Simmenthal”), Rec. 1978, 629, apartados 21 ss.; asunto C-213/89 ("Factortame I"), Rec. 1990, I-2433, apartados 19 ss.

${ }^{105}$ TJ, asunto C-119/05 (“Lucchini”), Rec. 2007, I-6199, apartados 49 ss., 62.

${ }^{106}$ TJ, asunto C-119/05 ("Lucchini”), Rec. 2007, I-6199, apartados 59, 63. El abogado general Geelhoed también acentuó en sus conclusiones sobre el asunto C-119/05 ("Lucchini"), Rec. 2007, I-6199 que la cosa juzgada de decisiones judiciales nacionales no debía hacer imposible el ejercicio de las competencias de la Comisión (apartados 47, 49 ss., sobre todo 69 ss.)

${ }^{107}$ Veáse ya arriba 4. El Tribunal de Justicia mismo también puso el problema jurídico del caso "Lucchini" en el contexto de los "principios del Derecho comunitario", que son aplicables para la revocación de un acto nacional, por el que se otorgaron ayudas en contra del Derecho comunitario: TJ, asunto C-119/05 ("Lucchini"), Rec. 2007, I-6199, apartado 1 . 
Derecho de la Unión, aparte de la situación especial del caso "Lucchini". Ya el abogado general Geelhoed lo llamó un "asunto extremadamente excepcional" en este sentido ${ }^{108}$. Sin embargo indicó que en los ordenamientos jurídicos nacionales sí existían excepciones de la cosa juzgada "sujetas a estrictos requisitos" y que por el Derecho comunitario también serían posibles excepciones en "casos especiales" 109 . Ahora nos toca esperar para ver esos casos particulares según el TJ.

\section{Resultados: ¿Reforzando o cuestionando la cosa juzgada?}

Desde una mirada global la jurisprudencia del TJ se muestra de una forma contradictoria después de este análisis. Por un lado, el TJ emite un mensaje explícito de que la cosa juzgada es un bien importante que no debería ser tocado. Eso se ve sobre todo en "Köbler", "Traghetti", y "Kapferer". En "Comisión/ Italia” se le atribuyó el incumplimiento del contrato al Legislador en vez de al Poder Judicial que era realmente responsable, para evitar una sentencia declaratoria en contra de los tribunales y sus sentencias que produjeron efecto de cosa juzgada. En "Kühne \& Heitz" la cosa juzgada no surge como tema realmente, sino se discute sobre todo la firmeza de una resolución administrativa. Por otro lado las conclusiones de los abogados generales sobre todo en los casos "Köbler", "Comisión/Italia" y "Kühne \& Heitz" transmiten otro mensaje, pues están cuestionando reiteradamente la cosa juzgada, como se podía ver en los pasajes citados anteriormente. Cuando aparte de todo eso el abogado general Tizzano propuso en "Kapferer", restringir "Kühne \& Heitz" a resoluciones administrativas el TJ evitó tomar postura frente a esa propuesta y dejó abierta la respuesta a que sería o no posible una corrección futura de la cosa juzgada bajo requisitos estrictos. En un caso muy especial el TJ hasta ordenó una limitación de la cosa juzgada ("Lucchini"). Finalmente, los fallos en "Köbler" y "Traghetti" están relativizando la cosa juzgada en el resultado porque sentencias judiciales pueden resultar en una responsabilidad del Estado.

¿Cómo se puede explicar entonces esa consecuencia irregular? En primer lugar hay que considerar que el TJ está en un diálogo con los tribunales nacionales en el cual quiere motivarlos a plantear más cuestiones prejudiciales según artículo 267 TFUE (antiguo artículo $234 \mathrm{CE}$ ) para obtener control sobre la aplicación efectiva y uniforme del Derecho de la Unión a través de esto. A excepción del caso "Lucchini", el TJ reacciona en los casos mencionados anteriormente a la disposición ausente de los tribunales de última

\footnotetext{
${ }^{108}$ Abogado general Geelhoed, conclusiones en el asunto C-119/05 ("Lucchini"), Rec. 2007, I-6199, apartado 16.

${ }^{109}$ Abogado general Geelhoed, conclusiones en el asunto C-119/05 ("Lucchini"), Rec. 2007, I-6199, apartados 36 ss., 37 (sobre el Derecho nacional), 46 (sobre el Derecho comunitario con referencia a "Köbler" y a "Kühne \& Heitz").
} 
instancia en cumplir con su obligación de plantear cuestiones prejudiciales según artículo 267 inciso $3^{\circ}$ TFUE (antiguo artículo 234 inciso $3^{\circ} \mathrm{CE}$ ) ${ }^{110}$. Los preceptos jurídicos desarrollados por el Tribunal en estas decisiones para motivar a los tribunales nacionales de plantear más cuestiones tienen tendencia a afectar de alguna manera la cosa juzgada de decisiones de última instancia. El caso "Köbler" muestra eso de la forma más impresionante. No siempre el TJ puede encontrar una forma de eludir la solución como en "Comisión/ Italia". Pero que el TJ evita limitar la cosa juzgada directamente en estos casos tiene su razón en el hecho que la cosa juzgada es un elemento esencial para el desarrollo (judicial) de un sistema de Derecho de la Unión y para su establecimiento judicial descentralizado en los ordenamientos jurídicos de los Estados miembros. Cuestionar la cosa juzgada abiertamente debilitaría demasiado la institución de tribunales y a través de eso también el desarrollo judicial normal del Derecho de la Unión. Solamente si una decisión de un tribunal de un Estado miembro que produjo efecto de cosa juzgada desacata de manera manifiesta la competencia de la Comisión en el sector del Derecho de ayudas, el TJ interviene refiriéndose al principio de la efectividad y limita la cosa juzgada de la decisión judicial nacional "Lucchini".

\section{POSIBLES OPCIONES PARA EL ORDENAMIENTO JURÍDICO NACIONAL}

La pregunta es cuál estrategia existe del punto de vista del Derecho nacional para reaccionar ante la erosión de la cosa juzgada, para impedir dicha erosión o quitarle su necesidad.

\section{Reanudación del proceso.}

Una sentencia del TJ donde constata el incumplimiento por un tribunal de última instancia sería un desafío para el ordenamiento jurídico nacional. Con respecto a la política actual de la Comisión y al planteamiento del TJ en "Comisión/Italia" no hay razón para esperar este escenario para el futuro próximo ${ }^{111}$. El ordenamiento jurídico nacional tiene que prepararse para esto

${ }^{110}$ Sobre esto más detallado Haltern, cit. (n. 47), pp. 327 ss. Con respecto a "Köbler" y "Comisión/Italia"; Haltern, cit. (n. 64), p. 330, habla de un "cambio de cooperación (no exitosa) a presión y control” (“Umstellung von (nicht erfolgreicher) Kooperation auf Zwang und Kontrolle”); véase, además, ibíd., pp. 183 s., 351 ss.

${ }^{111}$ Sin embargo, véase: LensKi, Edgar - MAYER, Franz C., Vertragsverletzung wegen Nichtvorlage durch oberste Gerichte?, en Europäische Zeitschrift für Wirtschaftsrecht, 16 (2005) 8, p. 225, sobre actuaciones preliminarias que la Comisión empezó contra Suecia por no plantear una cuestion por el Tribunal Supermo. Si la Comisión mientras tanto cambió su estrategia queda para esperar. 
y preguntarse, si no tendría que establecer medidas para revocar decisiones judiciales que están en contra del Derecho de la Unión. Como serán solamente excepciones especiales sería recomendable para Alemania cambiar las normas procesales según el modelo de $\$ 359$ No 6 StPO y $\$ 580$ No 8 ZPO. Con eso, con una excepción de la cosa juzgada, formulada inequívocamente y con seguridad jurídica, se podría corregir por el ordenamiento jurídico nacional en su mismo una decisión judicial que no es aceptable del punto de vista del Derecho de la Unión después del procedimiento del planteamiento de cuestiones prejudiciales ante el TJ.

\section{Procedimiento de una cuestión prejudicial.}

Los interlocutores que tiene el TJ son menos legisladores y más los tribunales nacionales. Estos no pueden aceptar a la larga que el Derecho de la Unión limite demasiado la cosa juzgada de sus decisiones permanentemente. Las correcciones de las decisiones judiciales por el TJ se harían menos necesarias si los tribunales nacionales hicieran participar más al TJ en los procesos de determinación que ellos mismos tienen sobre sus casos a resolver. Por la vía de un procedimiento prejudicial se pueden aclarar dudas sobre la interpretación del Derecho de la Unión, durante la sustanciación del proceso. Entonces es muy recomendable para los tribunales nacionales plantear más cuestiones prejudiciales, sobre todo los de última instancia que están obligados a plantear cuestiones según artículo 267 inciso $3^{\circ}$ TFUE (antiguo artículo 234 inciso $3^{\circ} \mathrm{CE}$ ). Por eso, a la larga será aún más necesaria una reforma del procedimiento de cuestiones prejudiciales para satisfacer las necesidades de resoluciones ${ }^{112}$. Por lo menos se puede constatar lo siguiente, si los tribunales nacionales plantearan a tiempo las cuestiones prejudiciales, se podría evitar infracciones como las ocurridas en "Köbler", “Traghetti”, “Comisión/Italia” y “Kühne \& Heitz”. Entonces, los tribunales nacionales pueden evitar problemas con la institución de la cosa juzgada a través de un planteamiento de cuestiones ante el TJ, impidiendo así que una decisión sea como en contra del Derecho de la Unión.

3. Recurso de amparo constitucional: Infracción del artículo 101 inciso $1^{\circ}$ frase $2^{a} G G$.

Finalmente existe la posibilidad del punto de vista alemán, de reforzar la obligación de plantear cuestiones prejudiciales y asegurar su cumplimiento a través de posibilitar un recurso de amparo constitucional

${ }^{112}$ Para más detalles sobre la discusión acerca de la reforma del procedimiento por cuestiones prejudiciales, consúltese: CRAIG - DE BÚRCA, cit. (n. 8), pp. 473 ss. 
("Verfassungsbeschwerde") ${ }^{113}$ contra el incumplimiento de ese deber de plantear la cuestión prejudicial. El TJ es un juez legal en el sentido de artículo 101 inciso $1^{\circ}$ frase $2 \mathrm{GG}^{114}$, por ende tribunales nacionales pueden infraccionar dicho artículo, al omitir plantear una cuestión prejudicial ante el $\mathrm{TJ}^{115}$. Conforme a la jurisprudencia actual del Bundesverfassungsgericht (BVerfG $=$ Tribunal Constitucional Federal Alemán) es requisito para el recurso de amparo constitucional que el tribunal no haya planteado cuestiones prejudiciales donde es evidentemente insostenible. El BVerfG desarrolló grupos de casos los cuales indican especialmente una infracción del artículo 101 inciso $1^{\circ}$ frase $2^{a} \mathrm{GG}$, si el tribunal de última instancia ignora de manera fundamental su obligación a plantear cuestiones, si discrepa conscientemente y sin disposición a plantear una cuestión prejudicial de la jurisprudencia del TJ y, si el tribunal - dado que la jurisprudencia del TJ está incompleta, pues excede de una forma no justificable la libre facultad que tiene en estos casos $^{116}$. Estas circunstancias se cumplirán raras veces. Frente al desarrollo actual de la jurisprudencia del TJ planteado arriba, el BVerfG podría considerar limitar los requisitos para la fundamentación de una infracción del artículo 101 inciso $1^{\circ}$ frase $2^{a} \mathrm{GG}$ para el caso de un incumplimiento con el artículo 267 inciso $3^{\circ}$ TFUE (antiguo artículo 234 inciso $3^{\circ} \mathrm{CE}$ ) ${ }^{117}$. De esa forma el ordenamiento jurídico alemán podría decidir por sí mismo corregir excepcionalmente decisiones judiciales de tribunales de última instancia,

${ }^{113}$ [N. d. T.: El Art. 93 inciso 1, N 4a GG dice: "El Tribunal Constitucional Federal Alemán decide sobre recursos de amparo constitucional, los cuales pueden ser interpuestos por cada persona con la afirmación de estar infringido por el poder público en uno de sus derechos fundamentales o en uno de sus derechos garantizados en los articulos 20 inciso 4, 33, 38, 101, 103 y 104"].

${ }^{114}\left[\right.$ [N. d. T.: el art. 101 inciso $1^{\circ}$ frase $2^{\text {a }}$ GG dice: “A nadie le puede ser privado su juez legal"].

${ }^{115}$ Véanse: BVerfGE, 73, pp. 366 ss.; 75, pp. 233 ss.; y 82, pp. 192 ss.. Sobre esto: Pieroth, Bodo, Kommentierung von Art. 101 GG, en Jarass, Hans - Pieroth, Bodo, Grundgesetz für die Bundesrepublik Deutschland. Kommentar ( $8^{a}$ edición, München, Beck, 2006), Art.101 GG, apartado 12; Wegener, cit. (n. 23), Art. 234 CE, apartado 31; MeIER, cit. (n. 47), pp. 13 s.; FASTEnRATh, Ulrich, Der Europäische Gerichtshof als gesetzlicher Richter, en Internationale Gemeinschaft und Menschenrechte. Festschrift für Georg Ress (Köln y otros, Heymanns, 2005), pp. 469 ss.

${ }^{116}$ Más detallado: BverfGE, 82, pp. 194 ss.; Neue Zeitschrift für Verwaltungsrecht (2005), p. 574; JuristenZeitung (2007), pp. 87 s., con comentario de PAEFGEN, Walter G., en Neue Zeitschrift für Verwaltungsrecht (2007), p. 198.

${ }^{117}$ Sobre la crítica contra la jurisprudencia del BVerfG, véase también: FASTENRATH, cit. (n. 115), sobre todo pp. 480 ss.; MEIER, cit. (n. 47), pp. 13 s. Sobre la pregunta de qué efectos tendría omitir un recurso de amparo constitucional contra la decisión judicial de última instancia, consúltese: SCHÖNDORF-Haubold, cit. (n. 35), p. 115; STORR, cit. (n. 35), pp. 549 s.; Wolf, cit. (n. 38), p. 1349. 
que produjeron efecto de cosa juzgada, a través de un procedimiento ante el BVerfG antes de que intervenga el TJ. Haciendo esto, el BVerfG aceptaría la oferta de cooperación del TJ el cual por lo menos según lo que el mismo ha dicho, no quiere afectar la cosa juzgada de decisiones nacionales.

[Recibido el 28 de agosto y aprobado el 21 de septiembre de 2010].

\section{BIBLIOGRAFÍA}

Literatura

Arnauld, Andreas von, Rechtssicherheit (Tübingen, Editorial Mohr Siebeck, 2006), $801 \mathrm{pp}$.

ARNull, Anthony, Interpretation and Precedent in European Community Law, en ANDENAS, Mads - JaCoBS, Francis (editores), European Community Law in the English Courts (Oxford, Editorial Oxford University Press, 1998), pp. 115-136.

Badura, Peter, Die Bedeutung von Präjudizien im öffentlichen Recht, en Blaurock, Uwe (editor), Die Bedeutung von Präjudizien im deutschen und französischen Recht (Frankfurt am Main, Editorial Metzner, 1985), pp. 49-74.

Bieber, Roland - Epiney, Astrid - HaAg, Marcel, Die Europäische Union ( $7^{\mathrm{a}}$ edición, Baden-Baden, Editorial Nomos, 2006), 597 pp.

BRAUn, Johann, Restitutionsklage wegen Verletzung der Europäischen Menschenrechtskonvention, en Neue Juristische Wochenschrift, 60 (2007) 23, pp. 1620-1622.

BREHM, Wolfgang, Rechtsfortbildungszweck des Zivilprozesses, en Festschrift für Ekkehard Schumann zum 70. Geburtstag (Tübingen, Mohr Siebeck, 2001), pp. 57-69.

BREUER, Marten, Urteile mitgliedstaatlicher Gerichte als möglicher Gegenstand eines Vertragsverletzungsverfahrens gem. Art. 226 EG?, en Europäische Zeitschrift für Wirtschaftsrecht, 15 (2004) 7, pp. 199-201.

Britz, Gabriele - Richter, Tobias, Die Aufhebung eines gemeinschaftsrechtswidrigen nicht begünstigenden Verwaltungsakts, en Juristische Schulung, 45 (2005) 3, pp. 198-202.

Clausing, Berthold, Kommentierung von \$121 VwGO (actualizado Febrero de 1996), en Schoсh, Friedrich - Schmidt-Assmann, Eberhard - Pietzner, Rainer (editores.), Verwaltungsgerichtsordnung. Kommentar (München, Beck, 1996).

Craig, Paul - De Búrca, Gráinne, EU Law (3ª edición, Oxford, Oxford University Press, 2003) $1241 \mathrm{pp}$.

Cremer, Wolfram, Kommentierung von Art. 226 EG, en Calliess, Christian - RuFFERT, Matthias (editores), EUV/EGV. Das Verfassungsrecht der Europäischen Union mit Europäischer Grundrechtecharta. Kommentar ( $3^{a}$ edicion, München, Beck, 2007), 2877 pp.

Detterbeck, Steffen, Streitgegenstand und Entscheidungswirkungen im Öffentlichen Recht (Tübingen, Mohr, 1995), 649 pp.

Eiranova Encinas, Emilio, Código Civil Alemán (Madrid, Marcial Pons, 1998), $720 \mathrm{pp}$.

FASTEnRath, Ulrich, Der Europäische Gerichtshof als gesetzlicher Richter, en Internationale Gemeinschaft und Menschenrechte. Festschrift für Georg Ress (Köln y otros, Heymanns, 2005), pp. 461-484. 
GäRDITZ, Klaus Ferdinand, Die Bestandskraft gemeinschaftsrechtswidriger Verwaltungsakte zwischen Kasuistik und Systembildung, en Nordrhein-Westfälische Verwaltungsblätter, 20 (2006) 12, pp. 441-449.

Grune, Jeanette, Staatshaftung bei Verstößen nationaler Gerichte gegen Europäisches Gemeinschaftsrecht, en Bayerische Verwaltungsblätter, 135 (2004) 22, pp. 673-677.

Gundel, Jörg, Bootsliegeplatz-Privilegien für Einheimische Verstoß gegen die Dienstleistungsfreiheit und Durchbrechung der nationalen Bestandskraft-Regeln?, en Europarecht, 34 (1999) 6, pp. 781-788.

GundEL, Jörg, Gemeinschaftsrechtliche Haftungsvorgaben für judikatives Unrecht - Konsequenzen für die Rechtskraft und das deutsche 'Richterprivileg'(5 839 Abs. 2 BGB), en Europäisches Wirtschafts- und Steuerrecht, 15 (2004) 1, pp. 8-16.

Haltern, Ulrich, Verschiebungen im europäischen Rechtsschutzsystem, en Verwaltungsarchiv, 96 (2005) 3, pp. 311-347.

Haltern, Ulrich, Europarecht (Tübingen, Mohr Siebeck, 2005), 690 pp.

Haratsch, Andreas, Anmerkung zum Urteil des EuGH v. 13.6.2006, Rs. C-173/03 (TDM/Italien), JuristenZeitung, 61 (2006) 23, pp. 1176-1178.

Hatje, Armin, Die Rechtskraft und ibre Durchbrechungsmöglichkeiten im Lichte des Gemeinschaftsrechts, en Holoubek, Michael - Lang, Michael (editores), Das EuGH-Verfahren in Steuersachen (Wien, Linde, 2000), pp. 133-149.

HergenRöDER, Curt Wolfgang, Zivilprozessuale Grundlagen richterlicher Rechtsfortbildung (Tübingen, Mohr, 1995), 530 pp.

KadelbaCH, Stefan, Allgemeines Verwaltungsrecht unter europäischem Einfluß (Tübingen, Mohr Siebeck, 1999), 560 pp.

Kadelbach, Stefan, Die Wirkung von im Vorabentscheidungsverfahren ergangenen Urteilen, en Holoubek, Michael - LANG, Michael (editores), Das EuGH-Verfahren in Steuersachen (Wien, Linde, 2000), pp. 119-132.

KENNTNER, Markus, Ein Dreizack für die offene Flanke Die neue EuGH-Rechtsprechung zur judikativen Gemeinschaftsrechtsverletzung, en Europäische Zeitschrift für Wirtschaftsrecht, 16 (2005) 8, pp. 235-238.

KLUTH, Winfried, Die Haftung der Mitgliedstaaten für gemeinschaftsrechtswidrige höchstrichterliche Entscheidungen. Schlussstein im System der gemeinschaftsrechtlichen Staatshaftung, en Deutsches Verwaltungsblatt, 119 (2004) 7, pp. 393-403.

Кокотт, Juliane - Henze, Thomas - Sовотта, Christoph, Die Pficht zur Vorlage an den Europäischen Gerichtshof und die Folgen ihrer Verletzung, en JuristenZeitung, 61 (2006) 13, pp. 633-641.

Komárex, Jan, Federal Elements in the Community Judicial System Building Coherence in the Community Legal Order, en Common Market Law Review, 42 (2005) 1, pp. 9-34.

Kopp, Ferdinand O. - Schenke, Wolf-Rüdiger, Verwaltungsgerichtsordnung. Kommentar (14 a edición, München, Beck, 2005), 2014 pp.

Kopp, Ferdinand O. - Ramsauer, Ulrich, Verwaltungsverfahrensgesetz ( $9^{a}$ edición, München, Beck, 2005), 1559 pp.

Kopp, Ferdinand O. - Kopp, Ferdinand J., Grenzen der Rechtskraftwirkung von Urteilen aufgrund von Anfechtungsklagen, en Neue Zeitschrift für Verwaltungsrecht, 13 (1994) 1, pp. 1-6.

Kremer, Carsten, Liability for Breach of European Community Law An Analysis of 
the New Remedy in the Light of English and German Law, en Yearbook of European Law, 22 (2003), pp. 203-247.

Kremer, Carsten, Staatshaftung für Verstöße gegen Gemeinschaftsrecht durch letztinstanzliche Gerichte, en Neue Juristische Wochenschrift, 57 (2004) 8, pp. 480-482.

Lames, Peter, Rechtsfortbildungals Prozeßzweck. Zur Dogmatik des Zivilverfahrensrechts (Tübingen, Mohr, 1993), 154 pp.

LARENZ, Karl, Methodenlehre der Rechtswissenschaft ( $6^{a}$ edición, Berlin y otros, Springer, 1991), $494 \mathrm{pp}$.

LenSKI, Edgar - MAYer, Franz C., Vertragsverletzung wegen Nichtvorlage durch oberste Gerichte? en Europäische Zeitschrift für Wirtschaftsrecht, 16 (2005) 8, p. 225.

LenZe, Anne, Die Bestandskraft von Verwaltungsakten nach der Rechtsprechung des EuGH, en Verwaltungsarchiv, 97 (2006) 1, pp. 49-61.

Lindner, Josef Franz, Anmerkung, en Bayerische Verwaltungsblätter, 135 (2004) 19, pp. 590-592.

Lindner, Josef Franz, Anmerkung, en Bayerische Verwaltungsblätter, 137 (2006) 22, pp. 696-697.

Ludwigs, Markus, Der Schutz der Rechtskraft im Gemeinschaftsrecht, Zugleich eine Anmerkung zur Kapferer-Entscheidung des EuGH, en Zeitschrift für Europarecht, Internationales Privatrecht und Rechtsvergleichung, 47 (2006) 5, pp. 191-194.

Ludwigs, Markus, Die Arcor-Entscheidung des EuGH Ein Beitrag zur Stärkung der mitgliedstaatlichen Verfahrensautonomie, en Neue Zeitschrift für Verwaltungsrecht, 26 (2007) 5, pp. 549-551.

MaUrer, Hartmut, Allgemeines Verwaltungsrecht (16 edición, München, Beck, 2006), $855 \mathrm{pp}$.

MAUrer, Hartmut, Introducción al derecho administrativo alemán (Bogotá, Editorial Universidad Santo Tomás, 2008), 123 pp.

Meder, Stephan, Die Krise des Nationalstaates und ibre Folgen für das Kodifikationsprinzip, en JuristenZeitung, 61 (2006) 10, pp. 477-484.

MEIER, Gert, Zur Einwirkung des Gemeinschaftsrechts auf nationales Verfahrensrecht im Falle höchstrichterlicher Vertragsverletzungen, en Europäische Zeitschrift für Wirtschaftsrecht, 2 (1991) 1, pp. 11-15.

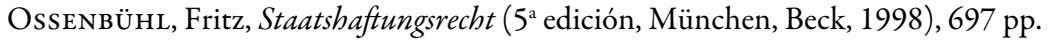

OssenbüHL, Fritz, Arten der Rechtsquellen, en ErichSEn, Hans-Uwe - EhLERs, Dirk (editores), Allgemeines Verwaltungsrecht (12 edición, Berlin, De Gruyter, 2002), $\$ 6,896 \mathrm{pp}$.

Paefgen, Walter G., Anmerkung, en JuristenZeitung, 62 (2007) 2, pp. 88-91.

Pieroth, Bodo, Kommentierung von Art. 101 GG, en Jarass, Hans D. - Pieroth, Bodo, Grundgesetz für die Bundesrepublik Deutschland. Kommentar ( $8^{\mathrm{a}}$ edición, München, Beck, 2006), 1193 pp.

PoтAcs, Michael, Bestandskraft staatlicher Verwaltungsakte oder Effektivität des Gemeinschaftsrechts? en Europarecht, 39 (2004) 4, pp. 595-602.

PотACs, Michael, Gemeinschaftsrecht und Bestandskraft staatlicher Verwaltungsakte, en Internationale Gemeinschaft und Menschenrechte. Festschrift für Georg Ress (Köln y otros, Heymanns, 2005), pp. 729-741.

RADERMACHER, Ludger, Gemeinschaftsrechtliche Staatshaftung für höchstrichterliche Entscheidungen, en Neue Zeitschrift für Verwaltungsrecht, 23 (2004) 12, pp. 14151421. 
Reichold, Klaus, Kommentierung vor $\$ 578 Z P O$, en Thomas, Heinz - Putzo, Hans, Zivilprozessordnung. Kommentar (28 a edición, München, Beck, 2007), 1705 pp.

Rennert, Klaus, Kommentierung von $\$ 121$ VwGO, en Eyermann, Erich, Verwaltungsgerichtsordnung. Kommentar (12 edición, München, Beck, 2006), 1433 pp.

RENNERT, Klaus, Bestandskraft rechtswidriger Verwaltungsakte und Gemeinschaftsrecht, en Deutsches Verwaltungsblatt, 122 (2007) 7, pp. 400-408.

Rosenberg, Leo - Schwab, Karl Heinz - GotTwald, Peter, Zivilprozessrecht (16 edición, München, Beck, 2004), 1391 pp.

Ruffert, Matthias, Anmerkung zum Urteil des EuGH v. 16.3.2006, Rs. C-234/04 (Kapferer), en JuristenZeitung, 61 (2006) 18, pp. 905-906.

Ruffert, Matthias, Wiederaufgreifen des Verfahrens, en Erichsen, Hans-Uwe Ehlers, Dirk (editores), Allgemeines Verwaltungsrecht (13 edición, Berlin, De Gruyter, 2006), $\$ 25$.

Ruffert, Matthias, Annotation Case C-173/03, Traghetti del Mediterraneo SpA in Liquidation v. Italian Republic, en Common Market Law Review, 44 (2007) 2, pp. 479-486.

Ruffert, Matthias, Anmerkung, en JuristenZeitung, 62 (2007) 8, pp. 407-409.

SACHS, Michael, 5 51, en STElkens, Paul - Bonk, Heinz Joachim - SACHS, Michael (editores), Verwaltungsverfahrensgesetz (6ª edición, München, Beck, 2001), 2739 pp.

SACK, Jörn, Verstoßverfahren und höchstrichterliche Vertragsverletzungen. Eine Klarstellung, en Europäische Zeitschrift für Wirtschaftsrecht, 2 (1991) 8, pp. 246 - 247.

SCHENKe, Wolf-Rüdiger, Verwaltungsprozessrecht (10ª edición, Heidelberg, C.F. Müller, 2005), 408 pp.

Scheuing, Dieter Helmut, Europäisierung des Verwaltungsrechts, en Die Verwaltung, 34 (2001) 1, pp. 107-143.

Schmidt-Assmann, Eberhard, Die Europäisierung des Verwaltungsverfahrensrechts, en Festgabe 50 Jahre Bundesverwaltungsgericht (Köln y otros, Heymanns, 2003), pp. 487-506.

Schmidt-Westphal, Oliver - Sander, Dirk, Anmerkung zum Urteil des EuGHv. 16.3.2006, Rs. C-234/04 (Kapferer), en Europäische Zeitschrift für Wirtschaftsrecht, 17 (2006) 8, pp. 242-244.

Schöndorf-Haubold, Bettina, Die Haftung der Mitgliedstaaten für die Verletzung von EG-Recht durch nationale Gerichte, en Juristische Schulung, 46 (2006) 2, pp. 112-115.

SEegers, Martin, Anmerkung, en Europäische Zeitschrift für Wirtschaftsrecht, 17 (2006) 18 , pp. 564-566.

Sellmann, Christian - Augsberg, Steffen, Entwicklungstendenzen des Vorlageverfahrens nach Art. 234 EGV, enDie Öffentliche Verwaltung, 59 (2006) 13, pp. 533-541.

Skouris, Vassilios, Rechtsfolgen der Verletzung des Europäischen Gemeinschaftsrechts durch oberste Gerichte der Mitgliedstaaten, en Für Sicherheit, für Europa. Festschrift für Volkmar Götz zum 70. Geburtstag (Göttingen, Vandenhoeck \& Ruprecht, 2005), pp. 223-238.

Sprau, Hartwig, Kommentierung von $\$ 826$ BGB, en Palandt, Otto, Bürgerliches Gesetzbuch (66ª edición, München, Beck, 2007), 2900 pp. 
STORR, Stefan, Abschied vom Spruchrichterprivileg? en Die Öffentliche Verwaltung, 57 (2004) 13, pp. 545-553.

STreinz, Rudolf, Europarecht (7ª edición, Heidelberg, C.F. Müller, 2005), 481 pp.

Streinz, Rudolf, Anmerkung zum Urteil des EuGH v. 16.3.2006, Rs. C-234/04 (Kapferer), en Juristische Schulung, 46 (2006) 7, pp. 637-639.

Suerbaum, Joachim, Die Europäisierung des nationalen Verwaltungsverfahrensrechts am Beispiel der Rückabwicklung gemeinschaftsrechtswidriger staatlicher Beihilfen, en Verwaltungsarchiv, 91 (2000) 2, pp. 169-208.

Tietjen, Daniel, Die Bedeutung der deutschen Richterprivilegien im System des gemeinschaftsrechtlichen Staatshaftungsrechts. Das EuGH-Urteil'Traghetti del Mediterraneo', en Europäisches Wirtschafts-und Steuerrecht, 18 (2007) 1, pp. 15-19.

Wattel, Peter J. - Köbler, Cilfit, We Can't Go on Meeting Like This, en Common Market Law Review, 41 (2004) 1, pp. 177-190.

Weatherill, Stephen - Beaumont, Paul, EU Law (3ª edición, London, Penguin Books, 1999), 1132 pp.

WEGENER, Bernhard W., Staatshaftungfür die Verletzungvon Gemeinschaftsrecht durch nationale Gerichte? en Europarecht, 37 (2002) 6, pp. 785-800.

Wegener, Bernhard W., Kommentierung von Art. 220 EG, en Calliess, Christian Ruffert, Matthias (editores), EUV/EGV. Das Verfassungsrecht der Europäischen Union mit Europäischer Grundrechtecharta. Kommentar ( $3^{a}$ edición, München, Beck, 2007), 2877 pp.

Windthorst, Kay, Begrenzung der Amtshaftung, en Detterbeck, Steffen - WinDTHORST, Kay - Sproll, Hans-Dieter, Staatshaftungsrecht (München, Beck, 2000), $\$ 10,479$ pp.

Wolf, Christian, Die (un-) dramatischen Auswirkungen der Köbler-Entscheidung des EuGH auf das gemeinschaftsrechtliche Staatshaftungsrecht und das deutsche Revisionsrecht, en Wertpapier-Mitteilungen, 59 (2005) 29, pp. 1345-1351.

Würtenberger, Thomas, Verwaltungsprozessrecht ( $2^{\mathrm{a}}$ edición, München, Beck, 2006), 309 pp.

Zweigert, Konrad - Kötz, Hein, Einführung in die Rechtsvergleichung ( $3^{a}$ edición, Tübingen, Mohr, 1996), 792 pp.

Jurisprudencia

Tribunal de Justicia de la Unión Europea

TJ, asunto 77/69 (Comisión/Bélgica), Rec. 1970, 237.

TJ, asunto 106/77 (Simmenthal), Rec. 1978, 629.

TJ, asunto 283/81 (CILFIT), Rec. 1982, 3415.

TJ, asunto 205-215/82 (Deutsche Milchkontor), Rec. 1983, 2633.

TJ, asunto C-213/89 (Factortame I), Rec. 1990, I-2433.

TJ, asunto C-24/95 (Alcan II), Rec. 1997, I-1591.

TJ, asunto C-126/97 (Eco Swiss), Rec. 1999, I-3055.

TJ, asunto C-224/97 (Ciola), Rec. 1999, I-2517.

TJ, asunto C-480/99 P (South Wales Small Mines Association), Rec. 2002, $\mathrm{I}-265$.

TJ, asunto C-129/00 (Comisión/Italia), Rec. 2003, I-14637.

TJ, asunto C-453/00 (Kühne \& Heitz), Rec. 2004, I-837.

TJ, asunto C-108/01 (Consorzio del Prosciutto di Parma), Rec. 2003, I-5121. 
TJ, asunto C-224/01 (Köbler), Rec. 2003, I-10239.

TJ, asunto C-440/01 P(R) (Artegodan GmbH), Rec. 2002, I-1489.

TJ, asuntos acumulados C-442/03 P y C-471/03 P (P \& O European Ferries y Diputación Foral de Vizcaya/Comisión), Rec. 2006, I-4845.

TJ, asunto C-459/02 (Gerekens), Rec. 2004, I-7315.

TJ, asunto C-173/03 (Traghetti), Rec. 2006, I-5177.

TJ, asunto C-402/03 (Skov), Rec. 2006, I-199.

TJ, asunto C-234/04 (Kapferer), Rec. 2006, I-2585.

TJ, asuntos acumulados C-392/04 y C-422/04 (i-21 u. Arcor), Rec. 2006, I-8559.

TJ, asunto C-119/05 (Lucchini), Rec. 2007, I-6199.

Conclusiones del Abogado General del Tribunal de Justicia

Abogado General Warner, conclusiones en el asunto 30/77 (Bouchereau), Rec. 1977, 1999.

Abogado General Tizzano, conclusiones en el asunto C-99/00 (Lyckeskog), Rec. 2002, I-4839.

Abogado General Geelhoed, conclusiones en el asunto C-129/00 (Comisión/Italia), Rec. 2003, I-14637.

Abogado General Léger, conclusiones en el asunto C-453/00 (Kühne \& Heitz), Rec. 2004, I-837.

Abogado General Léger, conclusiones en el asunto C-224/01 (Köbler), Rec. 2003, I-10239.

Abogado General Tizzano, conclusiones en el asunto C-234/04 (Kapferer), Rec. 2006, I-2585.

Abogado General Ruiz-Jarabo Colomer, conclusiones en el asuntos acumulados C-392/04 y C-422/04 (i-21 u. Arcor), Rec. 2006, I-8559.

Abogado General Geelhoed, conclusiones en el asunto C-119/05 (Lucchini), Rec. 2007, I-6199.

Abogado General Trstenjak, conclusiones en el asunto C-331/05 P (Internationaler Hilfsfonds e.V./Comisión), Rec. 2007, I-5475. $\mathrm{I}-411$.

Abogado General Bot, conclusiones en el asunto C-2/06 (Kempter), Rec. 2008,

Tribunal Europeo de Derechos Humanos

Tribunal Europeo de Derechos Humanos (Europäischer Gerichtshoffür Menschenrechte), Neue Juristische Wochenschrift 2004, 2647.

Tribunal Constitucional Federal Alemán (Bundesverfassungsgericht)

BVerfGE 82, 159.

BVerfGE 101, 361.

BVerfG, Neue Zeitschrift für Verwaltungsrecht 2005, 572.

BVerfG, JuristenZeitung 2007, 87.

Tribunal Federal Supremo Alemán (Bundesgerichtshof)

BGHZ 136, 182.

BGH, Neue Juristische Wochenschrift 2005, 1363. 
Tribunal Contencioso-Administrativo Federal (Bundesverwaltungsgericht) BVerwGE 70, 110.

BVerwGE 82, 272.

BVerwGE 92, 81.

BVerwGE 106, 328.

BVerwGE 121, 226.

BVerwG, Neue Zeitschrift für Verwaltungsrecht 2007, 709.

BVerwG, sentencia de 17.1.2007, $\mathrm{N}^{\circ}$ de ref. 6 C 33.06. 